\title{
Exosomal cargoes in OSCC: Current findings and potential functions
}

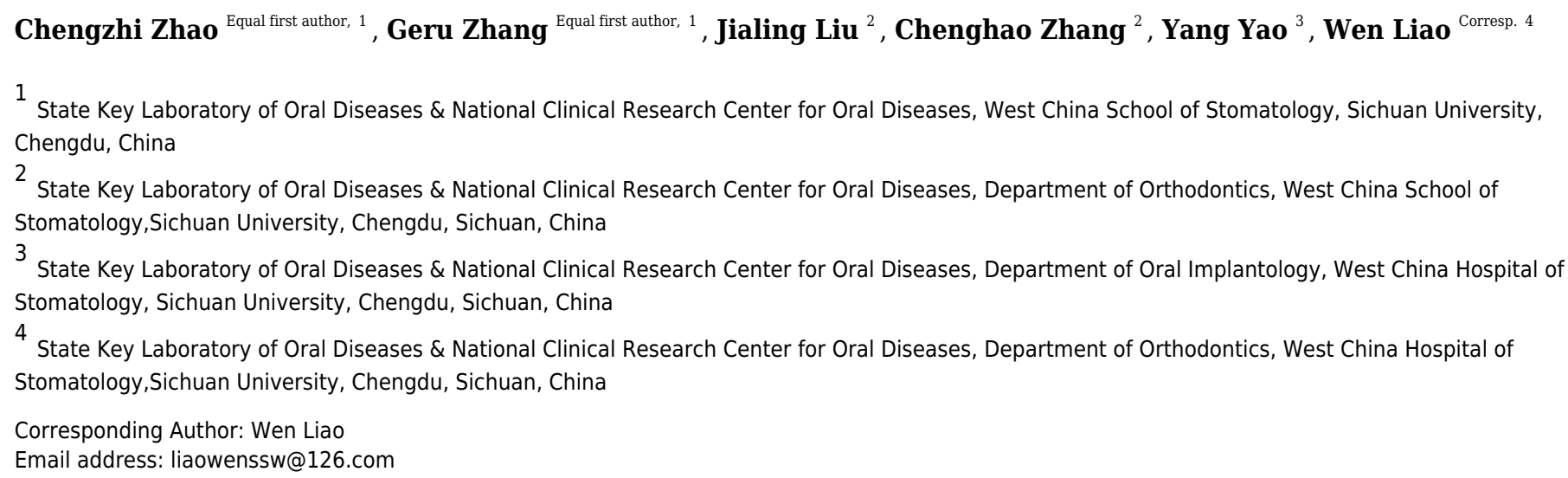

Oral squamous cell carcinoma (OSCC) is the most prevalent malignancy in head and neck cancer, with high recurrence and mortality. Early diagnosis and efficient therapeutic strategies are vital for the treatment of OSCC patients. Exosomes can be isolated from a broad range of different cell types, implicating them as important factors in the regulation of human physiological and pathological processes. Due to their abundant cargo including proteins, lipids, and nucleic acids, exosomes have played a valuable diagnostic and therapeutic role across multiple diseases, including cancer. In this review, we summarize recent findings concerning the content within, and participation of, exosomes relating to OSCC and their roles in tumorigenesis, proliferation, migration, invasion, metastasis, and chemoresistance. We conclude this review by looking ahead to their potential utility in providing new methods for treating OSCC to inspire further research in this field. 


\section{Exosomal cargoes in OSCC: current findings and 2 potential functions.}

3

4 5

6 7

Chengzhi Zhao ${ }^{1 \#}$, Geru Zhang ${ }^{1 \#}$, Jialing $\mathrm{Liu}^{2}$, Chenghao Zhang ${ }^{2}$, Yang $\mathrm{Yao}^{3}$, Wen Liao ${ }^{4 *}$ \# These two authors contribute equally to the manuscript.

${ }^{1}$ State Key Laboratory of Oral Diseases \& National Clinical Research Center for Oral Diseases, West China School of Stomatology, Sichuan University, Chengdu, Sichuan, China

${ }^{2}$ State Key Laboratory of Oral Diseases \& National Clinical Research Center for Oral Diseases, Department of Orthodontics, West China School of Stomatology, Sichuan University, Chengdu, Sichuan, China

${ }^{3}$ State Key Laboratory of Oral Diseases \& National Clinical Research Center for Oral Diseases, Department of Oral Implantology, West China Hospital of Stomatology, Sichuan University, Chengdu, Sichuan, China

${ }^{4}$ State Key Laboratory of Oral Diseases \& National Clinical Research Center for Oral Diseases, Department of Orthodontics, West China Hospital of Stomatology, Sichuan University, Chengdu, Sichuan, China

\section{Corresponding Author:}

Dr. Wen Liao

No.14, 3Rd Section of Ren Min Nan Rd. Chengdu, Sichuan 610041, China

Email address: liaowenssw@126.com

\section{Abstract}

Oral squamous cell carcinoma (OSCC) is the most prevalent malignancy in head and neck cancer, with high recurrence and mortality. Early diagnosis and efficient therapeutic strategies are vital for the treatment of OSCC patients. Exosomes can be isolated from a broad range of different cell types, implicating them as important factors in the regulation of human physiological and pathological processes. Due to their abundant cargo including proteins, lipids, and nucleic acids, exosomes have played a valuable diagnostic and therapeutic role in multiple diseases, including cancer. In this review, we summarize recent findings concerning the content within, and participation of, exosomes related to OSCC and their roles in tumorigenesis, proliferation, migration, invasion, metastasis, and chemoresistance. We conclude this review by looking ahead to their potential utility in providing new methods for treating OSCC, which hopefully inspires further research in this field.

\section{Introduction}

Extracellular vesicles (EVs) are membrane-bound organelles actively secreted by cells, which can be released by nearly all cell types and detected in many body fluids (Shah et al. 2018; Shao 
40 et al. 2018). The various types of cargo, including proteins, lipids, and nucleic acids within and

41 on EVs surface (Mashouri et al. 2019), vary depending on their parental cells of origin and

42 extracellular environment. This is why they are regarded as a mechanism for intercellular

43 communication (Shah et al. 2018; van Niel et al. 2018). Based on their morphological features

44 and contents, EVs are classified into different groups namely microvesicles (MVs), exosomes,

45 and apoptotic bodies (Gyorgy et al. 2011). Different EV subtypes are thought to be divided based

46 on their physical characteristics (such as size or density) relying on specific secretion

47 mechanism(Mathieu et al. 2019; Théry et al. 2018). Exosomes are one kind of EV with a

48 diameter of $<150 \mathrm{~nm}$ (Shah et al. 2018). They origin from intraluminal vesicles (ILVs) secreted

49 by multivesicular bodies (MVBs) through fusing with the plasma membrane (van Niel et al.

50 2018). Exosomes have been shown to play significant roles in regulating physiological and

51 pathological processes, in addition to having great potential in therapeutic development

52 (Ferguson \& Nguyen 2016; Kalluri \& LeBleu 2016; Liao et al. 2019; Mashouri et al. 2019).

53 Exosomes play important function in many diseases (Hadavand \& Hasni 2019; Kadota et al.

54 2016; Li et al. 2019b; Malm et al. 2016; Zhan et al. 2019). In cancer, their participation in

55 numerous process phases has been observed, including in situ tumorigenesis (Milman et al.

56 2019), tumor growth (Matei et al. 2017; Xue et al. 2017), angiogenesis (Zeng et al. 2018),

57 evasion of immune system (Chen et al. 2018; Kulkarni et al. 2019), resistance to

58 chemotherapeutic agents (Mashouri et al. 2019), and metastasis (Hoshino et al. 2015; Kulkarni et

59 al. 2019; Mashouri et al. 2019). In addition, antitumor effects have also been observed in

60 exosomes (Pakravan et al. 2017; Xie et al. 2019).

61 OSCC, usually preceded by white or red mucosal changes known as leukoplakia or

62 erythroplakia, respectively, or sometimes a combination of red and white features, is the most

63 prevalent malignancy of the head and neck (Chi et al. 2015) characterized by high recurrence and

64 poor prognosis. There are approximately 350,000-400,000 new cases each year with high risk of

65 recurrence (20\% to 30\%) (Gupta et al. 2016). Recently, a close association between OSCC and

66 exosomes biology has been reported. Exosomes can transport between cells and

67 microenvironment and promote the initiation and progression of OSCC directly (Momen-Heravi

68 \& Bala 2018; Razzo et al. 2019); they also modulate OSCC by regulating the immune system,

69 causing metabolic dysfunction and chemoresistance (Cui et al. 2020a). They have been

70 developed for applications in the clinic, including as biomarkers for early diagnosis and drug

71 delivery(de Jong et al. 2019; Surman et al. 2019; Zlotogorski-Hurvitz et al. 2016). In this

72 manuscript, we reviewed all these exciting advances. By looking ahead to exosomes' potential

73 utility in providing new methods for treating OSCC, we intend to inspire further research in this

74 field.

75

76

\section{Survey methodology}

77 We systematically searched with PubMed Advanced Search Builder with the following

78 keywords: (1) OSCC and exosomes, (2) HNSCC and exosomes, (3) proteins in exosomes and

79 OSCC, (4) lipid and exosomes and OSCC, (5) nucleic acids and exosomes in OSCC, (6) non- 
80

81

82

83

84

85

86

87

88

89

90

91

92

93

94

95

96

97

98

99

100

101

102

103

104

105

106

107

108

109

110

111

112

113

114

115

116

117

118

119

coding RNA and exosomes in OSCC, (7) mitochondrial DNA and exosomes in OSCC, (8) exosomes and clinic use and OSCC. By reading the titles and abstracts, papers nonrelated with either exosomal cargoes or OSCC or HNSCC were excluded. Besides, papers not published in English were excluded. Our search was not refined by publishing date, journal or impact factor of the journal, authors or authors affiliations.

\section{Exosomes biogenesis}

The biogenesis and release of exosomes to the extracellular environment is an ordered process. The first step for exosomes biogenesis is the formation of early endosomes (EEs). By inward budding or endocytosis, primary endocytic vesicles and their contents fuse with each other to form EEs (Huotari \& Helenius 2011; Liao et al. 2019). After the process of primary endocytic vesicles delivering their contents and membranes to EEs in the peripheral cytoplasm over 8-15 minutes, EEs will then go to their destination (Huotari \& Helenius 2011). One possible destination for EEs is recycling to the plasma membrane, directly or with the help of recycling endosomes (Huotari \& Helenius 2011; Morelli et al. 2004). The other possibility is their conversion to late endosomes (LEs) for additional processing. LEs accumulate ILVs formed by the inward budding of the endosomal membrane (Abels \& Breakefield 2016), which results in the conversion of LEs to MVBs (Abels \& Breakefield 2016; Liao et al. 2019). ILV formation is exquisitely regulated by mechanisms that remain to be fully elucidated, but it is reported to mainly rely on endosomal-sorting complex required for transport (ESCRT)-dependent machinery. Multiprotein ESCRT complexes are composed of ESCRT-0, ESCRT-I, ESCRT-II, and ESCRT-III. These localize on the cytoplasmic side of the endosomal membrane and play unique roles in sorting proteins into ILVs with assistance of accessory proteins (ALIX, VPS4, and VTA1) (Trajkovic et al. 2008). Besides ESCRT-dependent pathway, some evidence revealed that there are alternative, independent pathways regulating ILV biogenesis (Mashouri et al. 2019; McNally \& Brett 2018; Trajkovic et al. 2008). The type of cargo that is sorted into ILVs may relate to the mechanisms involved. With MVBs, there are two notable fates: to either degrade by fusing with lysosomes, or having their ILVs released as exosomes by fusion with the plasma membrane (Grant \& Donaldson 2009; Hessvik \& Llorente 2018). Exosomes biogenesis starting from the formation of EEs to the final release into extracellular environment is a complex process (Figure 1). To our knowledge, it can differ between cell types and their cellular physiological or pathological status (Kalluri \& LeBleu 2016; Liao et al. 2019), but much remains to be discovered to fully exploit the potential for exosomes as future clinical therapies (Mashouri et al. 2019).

\section{Exosomes capsuled protein in OSCC}

It is known that exosomes encapsulate genetic material as well as proteins from their cells of origin. Traditionally, the proteins that are encapsulated or transported by exosomes include structural and functional proteins that maintain the basic structure of exosomes and are responsible for regulating fusion, migration, and adhesion to target cells, such as transmembrane 
120 protein families (CD9, CD63, CD81 and CD82), molecular chaperones (Hsp70, Hsp90), multi121 capsule synthesis proteins (TSG101 and ALIX), membrane carried fusion proteins, and others 122 (Hemler 2003; Li et al. 2017a; Li et al. 2017b; van Niel et al. 2006). Some exosomes in cancer

123

124

125

126

127

128

129

130

131

132

133

134

135

136

137

138

139

140

141

142

143

144

145

146

147

148

149

150

151

152

153

154

155

156

157

158

159

tissues can carry specific proteins that allow their identification and differentiation from other exosomes, which could help to determine their unique function and potentially act as biomarkers for detecting disease progression (DeRita et al. 2017; Melo et al. 2015; Zhou et al. 2006).

In OSCC, exosomes-loaded protein both promote the tumorigenesis of OSCC and regulate the stromal cells around cancer tissues and support the processes of cancer cell proliferation (Figure 2).

Numerous studies have already revealed that epidermal growth factor receptor (EGFR) plays an important role in tumor growth progress including tumorigenesis, tumor invasion and drug resistance (Shostak \& Chariot 2015; Sigismund et al. 2018; Yang \& Chang 2018). In OSCC, there is no exception. Overexpression of EGFR activates many signal pathways, such as RAS/MEK/ERK, PI3K/AKT, and JAK/STAT pathways (Byeon et al. 2019; Nakamura et al. 2019; Oliveira-Silva et al. 2016; Zhang et al. 2018). Secretion of EGFR-contained exosomes from OSCC can be increased by EGF's stimulation. Vesicles internalized by healthy epithelial cells around cancer cells result in epithelial-mesenchymal transition (EMT), turning normal cell into spindle-like cells, which promotes invasion and migration of the cells within the milieu of tumor (Aiello et al. 2018). Fujiwara et al. established a novel mode of tumor therapy with antiEGFR antibody cetuximab. This drug inhibits EMT in oral epithelial cell by preventing the internalization of OSCC secreted exosomes into epithelial cells (Fujiwara et al. 2018). In the milieu of tumor, fibroblast is another crucial portion for its participation in oral cancer, and evidences show that exosomes can help it function better. Principe et al. compared fibroblasts from resected tumor, adjacent normal tissue in the same patient and conducted a detailed analysis of the cancer associated fibroblasts (CAF) secretome in OSCC. They found that CAF-derived exosomes loaded with cytokines, growth factors or chemokine were richer in tumor tissue than normal tissues, and exosomes play important role in promoting OSCC growth and migration. The major cargo in OSCC exosomes is microfibrillar-associated protein 5 (MFAP5), which is suggested to be a novel prognostic of OSCC and exosomes loaded with those content can be a new treat target (Principe et al. 2018). Jiang et al. found that OSCC cells can secrete exosomes with $\mathrm{p}$-ERK $1 / 2$ to adjacent normal fibroblasts, directly active the ERK1/2 signal pathway to down-regulate the expression of Caveolin-1 (CAV1) protein and up regulate the expression of MCT4 and PDK1 in normal fibroblasts. This regulation takes place both in vivo and in vitro and because of it, fibroblasts output much more lactate and cancer cells intake their outputted lactate, which then activates MCT4/MCT1 axis between cancer cell and activated fibroblasts, and, finally, provides sufficient energy for tumor cell growth and reproduction (Jiang et al. 2019). Interaction between tumor cells and immune system can play a dual role: on one hand, immune cells can recognize and eliminate tumor cells in the early stages of tumor development (Borst et al. 2018; Gardner \& Ruffell 2016; Teng et al. 2015); on the other hand, excessive infiltration of immune cells is related with poor prognosis (Gonzalez et al. 2018; Mantovani et al. 2017). In the

Peer) reviewing PDF | (2020:06:49854:1:1:NEW 26 Aug 2020) 
160

161

162

163

164

165

166

167

168

169

170

171

172

173

174

175

176

177

178

179

180

181

182

183

184

185

186

187

188

189

190

191

192

193

194

195

196

197

198

199

microenvironment of tumor, exosomes can mediate the reaction of immune cells (Figure 2). Kim et al. compared exosomes from normal and OSCC patients. They found that nearly $78 \%$ of OSCC patients' serum-derived exosomes express Fas ligand (FasL) and only 5\% exosomes in normal people express FasL. Moreover, co-culturing FasL (+) OSCC serum-derived exosomes with Jurkat cells lead to the apoptosis of immune cells (Kim et al. 2005). Zhang's group discovered that exosomes derived from supernatant of human oral cancer cells CAL 27 and SCC-25 (ATCC) were rich in interferon regulatory factor 3 (IRF-3) and its phosphorylation which promotes chemokine (C-X-C motif) ligand (CXCL) genes and the expression of the type I interferon (IFN) gene. This strengthenes the biological function of NK cells, including cytotoxicity, proliferation and release of granzyme $\mathrm{M}$ and perforin (Wang et al. 2018b). Chen and colleagues found that thrombospondin 1 (THBS1) was transported by OSCC-derived exosomes and could be taken into surrounding macrophages derived from THP-1 and PBMCs resulting in stimulating macrophage transformation into M1-like tumor associated macrophages (TAMs), this process plays a crucial role in controlling OSCC cell migration(Xiao et al. 2018). Besides, recent research indicates that transforming growth factor-beta (TGF- $\beta$ ) is important for tumorigenesis and immunosuppression in the tumor microenvironment(Batlle \& Massagué 2019); however, in OSCC, mutation of loss function in TGF $\beta$ type II receptor (T $\beta R I I)$ is quite common. South and colleagues discovered that exosomes extract from stromal fibroblasts isolated from OSCC patients contains T $\beta$ RII, they can increases TGF $\beta$ signaling in OSCC cells devoid of T $\beta$ RII, which active TGF- $\beta$ signaling between tumor cells and their surrounding microenvironment (Languino et al. 2016). They also showed that OSCC-derived exosomes were loaded with the C-terminal fragment of desmoglein 2, a highly expressed protein in many kinds of malignant tumors. DSG2 expression in OSCC could promote exosomes secretion through the modification of metalloproteases and repartitioning of Cav1; moreover, these DSG2-CTFpositive exosomes could modulate the microenvironment by converting nearby fibroblasts into TAMs(Overmiller et al. 2017).

In the past few years, several treatments have been conducted to the cancer patients, metastasis is still the major cause of death in most cases. Exosomes and their carriers secreted by cancer cells would participate in pathological generation of blood and lymphatic vessels, which is closely related to the development and progression of tumor tissues (Fu et al. 2019; Mashouri et al. 2019). Vascular endothelial growth factor C (VEGF-C) is universally acknowledged as one of the most effective proteins in promoting lymphatic vessels. It is abundant in lymph node positive metastatic OSCC patients (Lien et al. 2018; Shigetomi et al. 2018) (Figure 2). Zhong et al. discovered that increased VEGF-C expression associated with an increased number of salivary exosomes in OSCC tissues (Zhong et al. 2019). In Kozaki and colleagues' study, they found that the increase of HSP90-rich exosomes is positively correlated to the increased invasive capacity of OSCC; moreover the knockdown of HSP90 $\alpha$ and HSP90 $\beta$ decreased the metastatic capacity and survivability of OSCC cells (Ono et al. 2018). Observing that OSCC LN1-1 cells were more aggressive in lymphatic node metastasis than OEC-M1 cells, Wang et al. used stable isotope amino acid labeling to reveal that higher laminin-332 protein levels in tumor cell-derived 
200

201

202

203

204

205

206

207

208

209

210

211

212

213

214

215

216

217

218

219

220

221

222

223

224

225

226

227

228

229

230

231

232

233

234

235

236

237

238

239

exosomes was a major cause for the superior lymphangiogenesis ability of OSCC LN1-1 cells, as laminin-332 promotes lymphatic endothelial cell migration and tube formation (Wang et al. 2019a). Li et al. reported that PF4V1, CXCL7, F13A1, and ApoA1 could affect OSCC lymph node metastasis, and the mechanism remains unknown (Li et al. 2019a).

\section{Lipid cargo in OSCC exosomes}

Exosomes are an alternative means to carrier proteins and lipoproteins for transporting lipids(Record et al. 2014). There are approximately 2000 lipid species identified through comparative lipidomic analyses(Haraszti et al. 2016), which can localize to the membrane and lumen of exosomes. The roles for several kinds of lipids have been reported, including BMP (Bismonoacylglycerophosphate), cholesterols, ceramides, and phosphatidic acid(Record et al. 2014).These lipids play critical roles in exosomes biogenesis and release(Record et al. 2014; Record et al. 2018). And some of them can be unique and help us distinguish different EVs. For example, BMP is recognized as a lipidic molecule required for MVB formation(Subra et al. 2007) and ILV biogenesis(Falguières et al. 2012), however, it is irrelevant to the formations of MVs, which indicates its potential as a biomarker to distinguish exosomes from MVs(Record et al. 2018). Lipid composition is not only different between various EVs, the lipid contents of exosomes are usually different from their parental cells. Llorente et al. quantified 280 species of lipids from PC-3 prostate cancer cells and their exosomes and found some differences in their lipid composition(Llorente et al. 2013). This interesting finding indicates that the discrimination of lipids between exosomes and parental cells could play significant roles in many pathophysiologies, which inspires us that by detecting the lipid composition from exosomes and parental cells, it can be a diagnostic as well as therapeutic direction in the future. Over the past few years, lipid metabolic abnormalities have been identified as a feature of tumor cells. Hu et al. found that some lipid metabolism-related genes in OSCC patients could be used for prognostication (Hu et al. 2019). Lipid uptake can also be enhanced in cancer (Tousignant et al. 2019). Pascual et al. observed a similar phenomenon in OSCC, as they documented a subpopulation of CD44(bright) OSCC cells that express high levels of lipid metabolic genes and can initiate metastasis (Pascual et al. 2017).

Arachidonic acid (AA) is a free fatty acid that can be transported by exosomes (Subra et al. 2010), and its metabolism is a major dysregulated pathway in cancer cells (Gatto et al. 2016). As the precursor of both leukotrienes and prostaglandins, AA can be transferred between tissues by exosomes contributing to tumor growth and progression (Linton et al. 2018). Exosomes secreted from AsPC-1 cells, a highly metastatic pancreatic ductal adenocarcinoma cell line, were reported to deliver AA to macrophages. The fusogenicity of AsPC-1 exosomes decreased when pretreatment with PLA2 caused the removal of AA, indicating that exosomal AA may enhance crosstalk between cancer cells and TAMs, thus contributing to tumor progression (Linton et al. 2018). Besides AA itself, its products have been detected performing similar functions. Leukotrienes (LTs) are involved in various pathophysiologies such as inflammatory asthma, atherosclerosis, and cancer (Record et al. 2014). Several types of LTs, such as LTB4, LTC4, 
240 cysteinyl leukotriene LTC4, and LTC4 synthase, are enriched in exosomes (Esser et al. 2010; 241 Lukic et al. 2019). Exosomes appear to play a role in the biogenesis of LTs. For example, LTA4, 242 the precursor of leukotrienes, only has a five-second half-life in in vitro buffer, but with the 243 protection of exosomes, their half-life can be elongated to several minutes (Esser et al. 2010).

244 Besides assisting the biogenesis of LTs, exosomes seem to play other roles helping LTs 245 performing their pathological functions. Lukic et al. found that exogenous LTC4 generated by 246 monocytic cells can be transformed into pro-tumorigenic LTD4 through gamma-glutamyl 247 transpeptidase-1(GGT-1). GGT-1 is contained within both exosomes and primary cancer cells, 248

249

250

251

252

253

254

255

256

257

258

259

260

261

262

263

264

265

266

267

268

269

270

271

272

273

274

275

276

277

278

279 which stimulates cancer cell migration and survival(Esser et al. 2010). And since the 5lipoxygenase (5-Lox) and cyclooxygenase (COX)-2 pathways of arachidonic acid metabolism are involved in oral carcinogenesis (Lai et al. 2018), LTs in exosomes may also play an important role in OSCC. Prostaglandins (PGs) are another product of AA. Exosomes with high concentrations of prostaglandins transport more PGE2 to neighboring cells, enhancing the overall presence of PGE2 in the microenvironment(Subra et al. 2010). Cell motility and metastatic status are impacted by extracellular levels of PGE2(Nasry et al. 2018). Evidence has shown that exosomes rich in PGE2 participate in tumor immune evasion and promote tumor growth(Record et al. 2014). PGE2-mediated inflammation contributing to OSCC at different stages of carcinogenesis, invasion and metastasis contributes to patient morbidity and mortality(Harada et al. 2017). Abrahao et al. showed that HNSCC cells secrete PGE2. The overexpression of COX-2 in tumor and inflammatory cells, and subsequent increased production of PGE2, may promote HNSCC growth in an autocrine and paracrine way in the microenvironment. Exosomes can therefore be considered a potential medium for autocrine and paracrine regulation(Luga et al. 2012).

\section{Nucleic acids in OSCC exosomes}

A diverse collection of nucleic acids, including DNA, coding mRNA, non-coding RNA (ncRNA), micro RNA (miRNA), circular RNA (circRNA), and long non-coding RNA (lncRNA) have been identified in exosomes(Abels \& Breakefield 2016). The nucleic acid content of exosomes is believed to play a significant role in promoting cancer pathogenesis through the oncogenic transformation and transfer of cancer-specific genetic material(Kalluri \& LeBleu 2016). Understanding how nucleic acids transported by exosomes mediate the process of OSCC is critical, and could illuminate strategies for exosomes-based targeted therapy.

\subsection{DNA}

DNA in exosomes has been observed in cell culture supernatant as well as human and mouse biological fluids such as blood, seminal fluid, and urine(Kalluri \& LeBleu 2016). Based on cell origin, it is likely that different types of exosomes contain distinct types of DNA, such as singlestranded DNA (ssDNA), double-stranded DNA (dsDNA), mitochondrial DNA (mtDNA), and of varying states (e.g., fragment length, chromosome-bound)(Kalluri \& LeBleu 2016). Among these various types, dsDNA is the most evaluated(Kahlert et al. 2014). 
280 Exosomal DNA has been found to be involved in immunity regulation(Diamond et al. 2018; 281 Kitai et al. 2017). When tumors were treated by different strategies (e.g., antitumor drugs or 282 radiotherapy), the induced secretion of cancer cell-derived exosomes containing DNA triggered 283 dendritic cell (DC) activation and cytokine production, both of which can have antitumor effects 284 by regulating immune responses(Diamond et al. 2018; Kitai et al. 2017). In addition to its 285 potential therapeutic roles by regulating immune system, DNA in exosomes may become an 286 attractive candidate biomarker for tumor diagnosis because of the inherent stability of DNA 287 within exosomes(Kalluri \& LeBleu 2016). For example, the same mutations in susceptibility 288 genes were found in exosomal DNA and parental cells of pheochromocytomas and 289 paragangliomas(Wang et al. 2018a), and mutant KRAS, TP53, NOTCH1, and BRCA2 DNA in 290 exosomes from pancreatic cancer were also detected(San Lucas et al. 2016; Yang et al. 2017a). 291 Exosomes in OSCC may play similar roles, as mutant genes were discovered in OSCC cells as 292 well(Biswas et al. 2019; Natsuizaka et al. 2017).

293 Virus infection is closely related to cancers including OSCC. Moreover, viral DNA has also been 294 detected in exosomes from cancer patients(Yang et al. 2017b). For example, Meckes et al. 295 identified that ERK and PI3K/AKT signaling pathways can be activated if the recipient cells 296 were exposed to exosomes containing major EBV oncogene LMP1(Meckes et al. 2010). Besides, 297 Human papillomavirus (HPV) is considered a risk factor for OSCC, and its DNA has been found 298 in exosomes from HeLa cells(Mata-Rocha et al. 2020). There are some evidence demonstrating 299 that HPV DNA in exosomes participated in the process of cancer. HPV DNA in plasma-derived 300 exosomes was detected in rectal squamous cell carcinoma patients(Ambrosio et al. 2019).

301 Ambrosio et al. isolated exosomes from the HPV DNA-positive cell line CaSki, which can 302 transfer DNA to normal cell lines. Moreover, circulating exosomes-encapsulated HPV DNA in 303 the blood of neoplastic patients was verified to be transferred to normal and tumor cells at least 304 in vitro. Exosomes containing HPV are involved in HPV-associated carcinogenesis, indicating a 305 potential role in OSCC although there is no direct evidence noted(Guenat et al. 2017).

306 Mitochondria are major energy generators in cells, and increasing studies have revealed their role 307 in tumor development. Currently, scientists are deepening our understanding of the connections 308 between mitochondria and tumors. For example, cancer cells can obtain mitochondria from 309 healthy cells to achieve chemical resistance(Pasquier et al. 2013), and mitochondrial DAMP 310 provides tumor cells with a possible immune escape mechanism(Zhang et al. 2010a; Zhang et al. 311 2010b). The transfer of mitochondria or mtDNA is not completed independently, but is carried 312 out by the transporting mediators between cells, such as exosomes and secretory vesicles. In oral 313 cancer, whether exosomal mtDNA participates in tumorigenesis, tumor proliferation, and 314 migration is still vague. However, Uzawa et al. proposed a novel method for detecting mtDNA in 315 OSCC patients and reported significant differences in serum mtDNA levels before and after 316 OSCC patient treatment. They also identified mtDNA as a promising molecular marker for 317 OSCC prognostication(Uzawa et al. 2015). Despite these advances, further exploration into 318 exosomes-derived mtDNA and its application in the diagnosis and treatment of OSCC is 319 necessary. 
320

321

322

323

324

325

326

327

328

329

330

331

332

333

334

335

336

337

338

339

340

341

342

343

344

345

346

347

348

349

350

351

352

353

354

355

356

357

358

359

\section{$4.2 \mathrm{mRNA}$}

Coding mRNA has been found in exosomes. Transferring mRNA within exosomes can enable mRNA translation into proteins in recipient cells(Huang et al. 2013; Valadi et al. 2007), giving mRNA a potentially powerful role in cell-to-cell communication. Its function has been studied in both healthy and pathological states(Feng et al. 2018; Valadi et al. 2007). As a means for cell-tocell transportation, the mRNA profiles of tumor-derived exosomes have been evaluated in various cancers such as melanoma(Del Re et al. 2018), glioblastoma(Skog et al. 2008), prostate cancer(Lázaro-Ibáñez et al. 2017), and colorectal cancer(Hao et al. 2017). Moreover, these studies revealed that mRNAs in tumor-derived exosomes can play vital roles in promoting malignant tumor growth, proliferation, and metastasis through suppressing immune responses and resisting antitumor treatment (Del Re et al. 2018; Geis-Asteggiante et al. 2018; Skog et al. 2008).

Salivary liquid biopsy has emerged as an excellent method for disease detection, which is also applied to OSCC(Yakob et al. 2014). Evaluation of the salivary transcriptome from OSCC patients has helped to identify some mRNA biomarkers(Brinkmann et al. 2011). Qadir et al. characterized and compared the transcriptome profiles between exosomes isolated from primary human normal oral keratinocytes (HNOK) and HNSCC cell lines. The results showed that in HNSCC-derived exosomes, the expression of matrix remodeling (EFEMP1, DDK3, SPARC), cell cycle (EEF2K), membrane remodeling (LAMP2, SRPX), differentiation (SPRR2E), apoptosis (CTSC), and transcription/translation (KLF6, PUS7) factors showed significant differences from healthy cell-derived exosomes(Qadir et al. 2018), indicating that cancer cells may confer transcriptome reprogramming through exosomes to enhance cancer-associated pathologies.

\section{$4.3 n c R N A$}

Most of the human genome is considered biologically active. However, only a minor fraction of DNA encodes proteins. ncRNAs represent the majority of RNA that is not translated into proteins(Romano et al. 2017). NcRNAs are a category of exosomal cargo under investigation for its complex role in regulating gene expression(Zhang et al. 2015). NcRNA interactions are often interconnected which, when deregulated, could eventually drive tumorigenesis and progression(Chan \& Tay 2018). Identifying ncRNAs and their interactions will help to provide robust biomarkers and new therapeutic targets for more effective cancer therapies, better outcomes, and greater survival(Chan \& Tay 2018; Zhang et al. 2015) (Table 1).

\subsection{1 miRNA}

MiRNA are small ncRNAs around 22 nucleotides long, and they can be divided into oncogenic miRNA and tumor suppressor miRNA(Svoronos et al. 2016). They perform their posttranscriptional regulatory effects by binding to specific sites known as miRNA response elements (MREs) on their target transcripts, leading to either transcript degradation or 
360

361

362

363

364

365

366

367

368

369

370

371

372

373

374

375

376

377

378

379

380

381

382

383

384

385

386

387

388

389

390

391

392

393

394

395

396

397

398

399

translational inhibition(Chan \& Tay 2018). MiRNA regulatory activity in cancer has been widely studied(He et al. 2020; Li et al. 2019c; Sakha et al. 2016).

\subsubsection{Exosomal miRNAs in OSCC growth}

MiRNA function in OSCC has been thoroughly discussed(Langevin et al. 2017). Since they are secreted from various types of healthy and tumor cells(Tkach \& Théry 2016), miRNAs in exosomes can play different roles in promoting or inhibiting cancer. Dickman et al. found that miR-142-3p secreted from oral cancer cells promotes cancer cell growth by eliminating the miRNA tumor suppressive effect. Exosomes also promote tumor angiogenesis by releasing miR142-3p to its microenvironment(Dickman et al. 2017). However, in another study of Higaki et al(Higaki et al. 2020), overexpression of miR-6887-5p in SCC/OSCC cells inhibited tumor growth. Similar results document targeting miRNA as a treatment strategy to inhibit tumor growth. Lower levels of miR-3188 were detected in CAFs than normal fibroblasts, and loss of miR-3188 promoted malignant phenotypes in head and neck cancer cells, supporting its consideration as a therapeutic target(Wang et al. 2019c).

\subsubsection{Exosomal miRNAs in OSCC cell migration and invasion}

MiRNA in exosomes not only promote or inhibit tumor growth, but have also been shown to participate in OSCC cell migration and invasion. A research compared miRNA profiles in noninvasive SQUU-A and highly invasive SQUU-B tongue cancer cell clones, it was observed that hsa-miR-200c-3p acts within a key pro-invasion role in OSCC. The transfer of miR-200c-3p in exosomes derived from a highly invasive OSCC line can also accelerate the invasion potential of non-invasive counterparts(Kawakubo-Yasukochi et al. 2018). Another research done by Sun et al. also found that miR3825p was overexpressed in CAFs compared with fibroblasts of adjacent normal tissue, and miR3825p overexpression was an important regulatory factor in OSCC cell migration and invasion(Sun et al. 2019). MiRNAs in exosomes can also play like messengers to modulate tumor environment, and then manipulate OSCC cell migration and invasion. Normoxic and hypoxic OSCC-derived exosomes yielded different miRNA profiles, miR-21 showed its most significant role under hypoxic conditions. The loss of miR-21 in hypoxic OSCC cells downregulated miR-21 levels in exosomes and significantly reduced cell migration and invasion. Restoration of miR-21 expression in HIF- $1 \alpha$ - and HIF-2 $\alpha$-depleted exosomes rescued OSCC cell migration and invasion(Li et al. 2016).

\subsubsection{Exosomal miRNAs in OSCC metastasis}

Cancer metastasis is a very complicated process, involving intrinsic and extrinsic mechanisms. Metastasis is also a great challenge in our effort to fight cancer, and it caused poor prognosis of OSCC(Sun et al. 2019). It has been explosively studied and proved miRNAs participated in this process of OSCC. Some studies have noticed that cancer stem cell-derived extracellular vesicles are enriched with miR-21-5p, which is associated with increased potential of OSCC metastasis(Chen et al. 2019). However, some miRNAs have been revealed as performing anti- 
400 cancer roles as well. By examining the miRNA profiles of CAF- and normal fibroblast (NF)401 derived exosomes, miR-34a-5p expression was found to be significantly decreased, making it an 402 anti-cancer therapeutic target for OSCC(Li et al. 2018c). The complex of metastasis makes it a 403 fascinating field, especially the relations between miRNAs and tumor microenvironment (TME). 404 TME plays a vital role in the progression of OSCC. Recent research has revealed that tumor405 derived exosomes (TEX) accumulate in the TME and interact between tumor and healthy stromal cells(Ludwig et al. 2018). Cai et al. cocultured exosomes extracted from OSCC cell lines (SCC-9 and CAL-27) with macrophages. Their results showed that the upregulation of miR-29a$3 p$ in OSCC-derived exosomes is related to M2 subtype macrophage polarization. After interfering with miR-29a-3p from OSCC, M2 subtype macrophage polarization was inhibited by OSCC-derived exosomes(Cai et al. 2019).

411

412

413

\subsubsection{Exosomal miRNAs in chemoresistance}

414

415

416

417

418

419

420

421

422

423

424

425

426

427

428

429

430

431

432

433

434

435

436

437

438

439

Chemotherapy is a hallmark of fighting cancers. However, Chemoresistance is a significant challenge for OSCC treatment with no clear mechanism. Several studies have shown that miRNAs in exosomes of both healthy and tumor cells can manipulate this phenomenon(Cui et al. 2020b; Kirave et al. 2020; Qin et al. 2019). Some miRNAs are upregulated during chemotherapy, which can enhance chemoresistance against antitumor drugs such as cisplatin (CIS) and docetaxel (DTX). Kirave et al. found that when transferring exosomes from CISresistant to CIS-sensitive cells, miR-155 was significantly upregulated in the recipient CISsensitive cells(Kirave et al. 2020). Exosomes isolated from CIS-resistant cell lines contained a higher concentration of miR-21 in accordance with the parental cells' increased cisplatin resistance, which indicates that miR-21 may be a potential target against chemoresistance(Liu et al. 2017). The underlying mechanism is considered related to EMT and decreased DNA damage in cancer cells(Cui et al. 2020b; Kirave et al. 2020). Some miRNAs were downregulated during chemoresistance. For example, downregulation of miR-200c increased resistance to DTX, when miR-200c was transported by exosomes, the results showed the increase of the sensitivity to DTX both in vitro and in vivo, indicating miR-200c could be a therapeutic target of OSCC(Cui et al. 2020b).

\subsection{2 lncRNA and circRNA}

Beyond miRNA, there are other regulatory ncRNAs that perform complex roles in cancer(Morris $\&$ Mattick 2014). One kind, lncRNA, ranging from 200 to $>1000$ nucleotides, is a novel class in the human genome with seldom to no coding potential(Yang et al. 2015). They participate in various diseases through interacting with DNA(Lin et al. 2020), RNA, or proteins(Zhang et al. 2014). lncRNA may be involved in cancer cell proliferation(Wang et al. 2019b; Xu et al. 2019), migration(Xu et al. 2019), invasion(Xiong et al. 2019), metastasis(Jin et al. 2020; Xiong et al. 2019), and antitumor drug resistance(Wang et al. 2019b). LncRNA has multiple roles in regulating cancers, and the most important one among them is acting as "miRNA sponge"(Tan et al. 2019; Zhang et al. 2019b). Zhang et al. discovered that knockdown of lncRNA UCA1 
440 significantly suppressed TGF $\beta 1$-induced tongue cancer cell invasion and eventually induced 441 EMT(Zhang et al. 2019b). TGF $\beta 1$-induced EMT and invasion in OSCC are consistent with 442 increased JAG1, whereas miR-124 inhibits its expression. UCA1 binds to miR-124 directly and 443 can downregulate miR-124 expression. This is the basis for lncRNA UCA1's protumor effect

444

445

446

447

448

449

450

451

452

453

454

455

456

457

458

459

460

461

462

463

464

465

466

467

468

469

470

471

472

473

474

475

476

477

478

479 through sponge-like lncRNA-miRNA-mRNA regulation(Zhang et al. 2019b). lncRNA TIRY was also found to act as a miRNA sponge in OSCC by downregulating miR-14 expression in CAF-derived exosomes(Jin et al. 2020). lncRNA FLJ22447 (lnc-CAF) secreted from CAFs regulates NFs to CAFs, and tumor cells increased lnc-CAF levels in stromal fibroblasts via exosomal lnc-CAF as well(Ding et al. 2018). Unlike lncRNA, circRNA consists of a closed continuous loop structure without 5'-3' polarity or a poly-A tail, which enables its resistance to RNases and higher stability compared with linear RNA(Bai et al. 2019). Similar to lncRNA, circRNA also functions as a miRNA sponge(He et al. 2019). Although the roles of circRNA in exosomes remains unknown, a hypothesis has been introduced by Bai et al(Bai et al. 2019). Some circRNAs may bind to and transport with miRNAs by exosomes. After entering target cells, miRNAs are released to regulate target genes(Jin et al. 2020). CircRNAs in exosomes may therefore enter the recipient cells, bind to miRNAs, and regulate target genes. The roles of circRNAs in OSCC have been investigated by several researchers(Han et al. 2020), and differences in circRNAs profiles between OSCC patients and healthy people have also been distinguished(Qiu et al. 2019; Wei et al. 2020). By performing the function of miRNA sponge, the significance of LncRNA and circRNA has been noted, their discovery in OSCC also indicates that their roles in the pathogenesis cannot be neglected. Although there is still a lack of direct evidence for exo-lncRNA and exo-circRNA regulating OSCC, the evidence presented in other cancers proved it must be a remarkable field in the future research of OSCC as well (Li et al. 2018a; Li et al. 2018b; Ren et al. 2018; Zhang et al. 2019a).

\subsubsection{Other ncRNAs}

Besides regulatory ncRNA, tRNA and rRNA make up another group of ncRNA referred to as housekeeping ncRNA(Romano et al. 2017). Baglio et al. defined the exosomes-enclosed RNA species from the full small RNAome of MSC-produced exosomes(Baglio et al. 2015). Adipose and bone marrow MSC subtypes secrete different tRNA species that may be relevant to clinical applications; however, how tRNAs are transported through exosomes and their influence on the microenvironment in a cell type-dependent manner remains unclear(Baglio et al. 2015).

Crescitelli et al. analyzed RNA profiles in different EVs including exosomes. According to their findings, rRNA was primarily detectable in apoptotic bodies, but smaller RNAs without prominent ribosomal RNA peaks in exosomes(Crescitelli et al. 2013). This indicates that exosomes are potentially not carriers of rRNA. Collectively, there is little evidence surrounding the exosomal transportation of tRNA and rRNA, let alone their potential function in modulating cancer and their microenvironment.

\section{Clinical use of exosomes}


$480 \quad 5.1$ Exosomes as biomarkers for diseases diagnosis

481 Combining exosomes' stability and accessibility in various biological fluids like urine, blood

482 (including serum), breast milk, exosomes can be used as biomarkers for various cancers, some

483 can even be used to determine the type and severity of the disease. For example, exosomes

484 carrying Glypican-1 are considered a sensitive indicator of pancreatic cancer in blood

485 samples(Melo et al. 2015). In gastric cancer patients, exosomes expressing CD63 can be isolated

486 from tumor cells cluster but not stromal cells reflects a worse prognosis than the situation that

487 CD63+ exosomes can be find in both cell types (Miki et al. 2018). As for OSCC, exosomes have

488 also been considered as one of the fast-detected methods for they have been discovered in the

489 tumor microenvironment and been discovered play an irreplaceable role in OSCC's

490 tumorigenesis, tumor proliferation and migration, tumor invasion and metastasis(including

491 angiogenesis and lymphangiogenesis), chemoresistance, and so on (Figure 3). Many studies have

492 shown that the morphology and content of exosomes isolated from OSCC patients' saliva and

493 blood are very different from that of healthy people, suggested the possibility of using exosomes

494 for OSCC diagnosed(Zlotogorski-Hurvitz et al. 2016). By using high-resolution AFM, Sharma et

495 al. found the salivary exosomes of oral cancer patients were much larger and amorphous

496 compared with those of healthy people, and also found that CD63 was significantly increased on

497 the surface of cancer exosomes(Sharma et al. 2011). In a study by Rabinowits, tongue squamous

498 cell carcinoma tissue and normal tissue were collected in pairs. They isolated exosomes and

499 found different miRNA loading patterns similar to the loading patterns of blood exosomes,

500 suggesting that circulating exosomes can be a more reliable method in evaluating

501 tumors(Rabinowits et al. 2017). Sanada et al. examined the expression levels of secreted lysyl-

502 oxidase-like 2 (LOXL2) in pharyngeal and tongue cancer patient serum and found that elevated

503 serum exosomes LOXL2 levels are associated with low-grade oral cancer(Sanada et al. 2020).

504 All these discoveries of exosomes provide new ideas for the non-invasive disease diagnosis

505 method.

506 Also, the contents of exosomes can indicate tumor invasion capacity and occurrence of distant

507 metastasis, because exosomes always participate in the angiogenesis and lymphangiogenesis of

508 tumor tissues as mentioned before. Li and colleagues found that miR-21-rich exosomes are

509 associated with increased OSCC invasiveness, and that these exosomes are delivered to

510 normoxic cells to promote prometastatic behaviors(Li et al. 2016). Nakashima et al. utilized

511 integrated microarray profiling technology to analyze the different expression patterns of

512 miRNA between non-invasive and highly invasive tongue cancer cells, observing that hsa-miR-

513 200c-3p was the crucial point in spreading invasive ability(Kawakubo-Yasukochi et al. 2018).

514 Moreover, the quantity and content of exosomes can be used in non-invasive examination for

515 deciding tumor stages and predict the prognosis of treated OSCC patients, and scientists

516 suggested that the combination of different kinds of biomarkers are significantly better than

517 single biomarker in OSCC diagnosing. Ludwig et al. suggest that tumor staging can be

518 understood by exploring the interaction between OSCC cell-derived exosomes and lymphocytes.

519 Exosomes in the plasma of patients with tumors in an uncontrolled phase have greater induction 
520 of $\mathrm{T}$ cell apoptosis and inhibition of lymphocyte proliferation, which differs from patients 521 without significant disease(Ludwig et al. 2017). The quantity and content of exosomes could 522 predict the prognosis of treated OSCC patients. Liu and Tian compared serum exosomes between 523 laryngeal squamous cell carcinoma patients and vocal cord nodule patients, finding that the 524 expression levels of miR-21 and HOTAIR were higher in exosomes of malignant lesions.

525 Moreover, the serum exosomes of patients with laryngeal cancer in stage III/IV also showed a 526 high level of miR-21 and HOTAIR in exosomes(Wang et al. 2014), suggesting an association 527 between the level of exosomal content and prognosis. Those outcomes are similar to a clinical

528

529

530

531

532

533

534

535

536

537

538

539

540

541

542

543

544

545

546

547

548

549

550

551

552

553

554

555

556

557

558

559 study performed by Zorrilla et al., they collected ten OSCC patients' plasma sample before and after the excision surgery to evaluate the level of plasmatic CD63+ and CAV1+ exosomes levels correlate with patient's overall survival, they came to an conclusion that the lower expression of CD63+ exosomes after surgery and lower CAV1+ exosomes before surgery would indicate a longer life expectancy (Rodríguez Zorrilla et al. 2019).

\subsection{Exosomes as therapeutic mediums}

In terms of exosomal structure, they consist of biogenic lipid bilayers similar to cell membranes, which could protect cargo from degradation and could deliver the drug to target cells. The surface diameter of exosomes is only $40-150 \mathrm{~nm}$, so they are small enough to access most tissue without consumption and degradation by macrophages(de Jong et al. 2019; Kalluri \& LeBleu 2016; Surman et al. 2019; Vader et al. 2016; Yang \& Wu 2018). Moreover, they may exhibit inherent targeting properties, which is determined by lipid composition and protein content(Murphy et al. 2019). With these advantages, they are considered as potential drug delivery systems. At present, clinical trials using exosomes as a drug delivery method against cancer have been gradually increasing. In lung cancer, tumor cell-derived exosomes were extracted from the pleural effusion of lung cancer patients. After modification and loading with the chemotherapy drug methotrexate, they were reinjected into the patient's chest cavity. It has been observed that exosomes have a safe inhibitory effect on the growth of tumor cells(Guo et al. 2019). In colon cancer, exosomes with carcinoembryonic antigen were isolated from ascites fluid. After combining them with granulocyte macrophage colony stimulating factor, they served as a vaccine to induce a beneficial tumor-specific antitumor cell toxic $\mathrm{T}$ lymphocyte response(Dai et al. 2008). In OSCC, the current drug-loading process is mainly based on different carrier systems, such as nanoparticles, nanolipids, and hydrogels, which can alleviate the disadvantage of poor water solubility for oral cancer anti-cancer drugs to a certain extent(Ketabat et al. 2019; Luo et al. 2014; Poonia et al. 2017). Studies have shown that exosomes have been used as carriers for chemotherapeutic agents such as curcumin, DOX, and PTX, thereby reducing their side effects and improving therapeutic efficiency(Batrakova \& Kim 2015; Sun et al. 2010; Tian et al. 2014). Despite this progress, research on exosomes as a drugloading system is still limited, mainly due to their limited ability to deliver high-dose therapeutic drugs, insufficient basic experiments, and a lack of effective, standardized separation and purification methods(Ludwig et al. 2019; Yang \& Wu 2018). 
560

561

562

563

564

565

566

567

568

569

570

571

572

573

574

575

576

577

578

579

580

581

582

583

584

585

586

587

588

589

590

591

592

593

594

595

596

597

598

599

600

601

\section{Conclusions}

Researchers are continuing to provide new evidences on the importance of exosomes in cancer tumorigenesis, proliferation, migration, invasion, metastasis, and chemoresistance. Exosomal cargo based drug delivery system is also interesting in the treatment of OSCC because of its numerous type and abundance of cargo found in OSCC-related exosomes, which varies among different states of health and disease. What is more, because of their unique secretion patterns, exosomes can be used as ideal biomarkers for OSCC diagnosis, especially in saliva biopsy, which is a non-invasive method comparing to serum biopsy. With all these possibilities, however, there is still a lot not clearly understand in exosomes generation, secretion, cargo transportation, fusion with target membrane, especially the consistent test standard and separation method of exosomes has not been completely established. A more comprehensive understanding of the complexity of exosomes would help us elucidate disease mechanisms and provide opportunities for the diagnosis and treatment of OSCC. The safety of exosomes is still another question not solved yet. Further studies in this field, such as clinical study or studies using large animal models, are still needed to prove exosomes' safety in treatment, especially for exosomes secreted from cancer cells. Despite the faced great challenges and difficulty, we still find exosomes' great potential of usage in OSCC treatment and biopsy. We believe that exosomes can play even more important role in this field.

\section{Acknowledgements}

We acknowledge Dr. Qiang Peng for his valuable suggestion.

This study was supported by National Natural Science Foundation of China (No. 81700941), the Science and Technology Department of Sichuan Province (20ZDYF2839) and 2018 Sichuan University-Luzhou City co-operation program (CDLZ2018-14). The funding body was not involved in the design of the study; collection, analysis or interpretation of the data; or in writing the manuscript.

\section{Refereces}

Abels ER, and Breakefield XO. 2016. Introduction to Extracellular Vesicles: Biogenesis, RNA Cargo Selection, Content, Release, and Uptake. Cell Mol Neurobiol 36:301-312. 10.1007/s10571-016-0366-z

Aiello NM, Maddipati R, Norgard RJ, Balli D, Li J, Yuan S, Yamazoe T, Black T, Sahmoud A, Furth EE, Bar-Sagi D, and Stanger BZ. 2018. EMT Subtype Influences Epithelial Plasticity and Mode of Cell Migration. Dev Cell 45:681-695.e684. 10.1016/j.devcel.2018.05.027

Ambrosio MR, Vernillo R, De Carolis S, Carducci A, Mundo L, Ginori A, Rocca BJ, Nardone V, Lucenti Fei A, Carfagno T, Lazzi S, Cricca M, and Tosi P. 2019. Putative Role of Circulating Human Papillomavirus DNA in the Development of Primary Squamous Cell Carcinoma of the Middle Rectum: A Case Report. Front Oncol 9:93. 10.3389/fonc. 2019.00093 
602

603

604

605

606

607

608

609

610

611

612

613

614

615

616

617

618

619

620

621

622

623

624

625

626

627

628

629

630

631

632

633

634

635

636

637

638

639

640

641

642

643

644

645

646

647

648

649

650

651

Baglio SR, Rooijers K, Koppers-Lalic D, Verweij FJ, Pérez Lanzón M, Zini N, Naaijkens B, Perut F, Niessen HW, Baldini N, and Pegtel DM. 2015. Human bone marrow- and adiposemesenchymal stem cells secrete exosomes enriched in distinctive miRNA and tRNA species. Stem Cell Res Ther 6:127. 10.1186/s13287-015-0116-z

Bai H, Lei K, Huang F, Jiang Z, and Zhou X. 2019. Exo-circRNAs: a new paradigm for anticancer therapy. Mol Cancer 18:56. 10.1186/s12943-019-0986-2

Batlle E, and Massagué J. 2019. Transforming Growth Factor- $\beta$ Signaling in Immunity and Cancer. Immunity 50:924-940. 10.1016/j.immuni.2019.03.024

Batrakova EV, and Kim MS. 2015. Using exosomes, naturally-equipped nanocarriers, for drug delivery. J Control Release 219:396-405. 10.1016/j.jconrel.2015.07.030

Biswas NK, Das C, Das S, Maitra A, Nair S, Gupta T, D'Cruz AK, Sarin R, and Majumder PP. 2019. Lymph node metastasis in oral cancer is strongly associated with chromosomal instability and DNA repair defects. Int J Cancer 145:2568-2579. 10.1002/ijc.32305

Borst J, Ahrends T, Bąbała N, Melief CJM, and Kastenmüller W. 2018. CD4(+) T cell help in cancer immunology and immunotherapy. Nat Rev Immunol 18:635-647.

10.1038/s41577-018-0044-0

Brinkmann O, Kastratovic DA, Dimitrijevic MV, Konstantinovic VS, Jelovac DB, Antic J, Nesic VS, Markovic SZ, Martinovic ZR, Akin D, Spielmann N, Zhou H, and Wong DT. 2011. Oral squamous cell carcinoma detection by salivary biomarkers in a Serbian population. Oral Oncol 47:51-55. 10.1016/j.oraloncology.2010.10.009

Byeon HK, Ku M, and Yang J. 2019. Beyond EGFR inhibition: multilateral combat strategies to stop the progression of head and neck cancer. Exp Mol Med 51:1-14. 10.1038/s12276018-0202-2

Cai J, Qiao B, Gao N, Lin N, and He W. 2019. Oral squamous cell carcinoma-derived exosomes promote M2 subtype macrophage polarization mediated by exosome-enclosed miR-29a3p. Am J Physiol Cell Physiol 316:C731-c740. 10.1152/ajpcell.00366.2018

Chan JJ, and Tay Y. 2018. Noncoding RNA:RNA Regulatory Networks in Cancer. Int J Mol Sci 19. $10.3390 /$ ijms 19051310

Chen G, Huang AC, Zhang W, Zhang G, Wu M, Xu W, Yu Z, Yang J, Wang B, Sun H, Xia H, Man Q, Zhong W, Antelo LF, Wu B, Xiong X, Liu X, Guan L, Li T, Liu S, Yang R, Lu Y, Dong L, McGettigan S, Somasundaram R, Radhakrishnan R, Mills G, Lu Y, Kim J, Chen YH, Dong H, Zhao Y, Karakousis GC, Mitchell TC, Schuchter LM, Herlyn M, Wherry EJ, $\mathrm{Xu}$ X, and Guo W. 2018. Exosomal PD-L1 contributes to immunosuppression and is associated with anti-PD-1 response. Nature 560:382-386. 10.1038/s41586-018-0392-8

Chen JH, Wu ATH, Bamodu OA, Yadav VK, Chao TY, Tzeng YM, Mukhopadhyay D, Hsiao M, and Lee JC. 2019. Ovatodiolide Suppresses Oral Cancer Malignancy by DownRegulating Exosomal Mir-21/STAT3/3-Catenin Cargo and Preventing Oncogenic Transformation of Normal Gingival Fibroblasts. Cancers (Basel) 12. $10.3390 /$ cancers 12010056

Chi AC, Day TA, and Neville BW. 2015. Oral cavity and oropharyngeal squamous cell carcinoma--an update. CA Cancer J Clin 65:401-421. 10.3322/caac.21293

Crescitelli R, Lasser C, Szabo TG, Kittel A, Eldh M, Dianzani I, Buzas El, and Lotvall J. 2013. Distinct RNA profiles in subpopulations of extracellular vesicles: apoptotic bodies, microvesicles and exosomes. J Extracell Vesicles 2. 10.3402/jev.v2i0.20677

Cui J, Wang H, Zhang X, Sun X, Zhang J, and Ma J. 2020a. Exosomal miR-200c suppresses chemoresistance of docetaxel in tongue squamous cell carcinoma by suppressing TUBB3 and PPP2R1B. Aging (Albany NY) 12:6756-6773. 10.18632/aging.103036

Cui J, Wang H, Zhang X, Sun X, Zhang J, and Ma J. 2020b. Exosomal miR-200c suppresses chemoresistance of docetaxel in tongue squamous cell carcinoma by suppressing TUBB3 and PPP2R1B. Aging (Albany NY) 12:6756-6773. 10.18632/aging.103036

Peer) reviewing PDF | (2020:06:49854:1:1:NEW 26 Aug 2020) 
652

653

654

655

656

657

658

659

660

661

662

663

664

665

666

667

668

669

670

671

672

673

674

675

676

677

678

679

680

681

682

683

684

685

686

687

688

689

690

691

692

693

694

695

696

697

698

699

700

701

702

Dai S, Wei D, Wu Z, Zhou X, Wei X, Huang H, and Li G. 2008. Phase I clinical trial of autologous ascites-derived exosomes combined with GM-CSF for colorectal cancer. $\mathrm{Mol}$ Ther 16:782-790. 10.1038/mt.2008.1

de Jong OG, Kooijmans SAA, Murphy DE, Jiang L, Evers MJW, Sluijter JPG, Vader P, and Schiffelers RM. 2019. Drug Delivery with Extracellular Vesicles: From Imagination to Innovation. Acc Chem Res 52:1761-1770. 10.1021/acs.accounts.9b00109

Del Re M, Marconcini R, Pasquini G, Rofi E, Vivaldi C, Bloise F, Restante G, Arrigoni E, Caparello C, Bianco MG, Crucitta S, Petrini I, Vasile E, Falcone A, and Danesi R. 2018. PD-L1 mRNA expression in plasma-derived exosomes is associated with response to anti-PD-1 antibodies in melanoma and NSCLC. Br J Cancer 118:820-824. 10.1038/bjc.2018.9

DeRita RM, Zerlanko B, Singh A, Lu H, lozzo RV, Benovic JL, and Languino LR. 2017. c-Src, Insulin-Like Growth Factor I Receptor, G-Protein-Coupled Receptor Kinases and Focal Adhesion Kinase are Enriched Into Prostate Cancer Cell Exosomes. J Cell Biochem 118:66-73. 10.1002/jcb.25611

Diamond JM, Vanpouille-Box C, Spada S, Rudqvist NP, Chapman JR, Ueberheide BM, Pilones KA, Sarfraz Y, Formenti SC, and Demaria S. 2018. Exosomes Shuttle TREX1-Sensitive IFN-Stimulatory dsDNA from Irradiated Cancer Cells to DCs. Cancer Immunol Res 6:910-920. 10.1158/2326-6066.Cir-17-0581

Dickman CT, Lawson J, Jabalee J, MacLellan SA, LePard NE, Bennewith KL, and Garnis C. 2017. Selective extracellular vesicle exclusion of miR-142-3p by oral cancer cells promotes both internal and extracellular malignant phenotypes. Oncotarget 8:1525215266. 10.18632/oncotarget. 14862

Ding L, Ren J, Zhang D, Li Y, Huang X, Hu Q, Wang H, Song Y, Ni Y, and Hou Y. 2018. A novel stromal IncRNA signature reprograms fibroblasts to promote the growth of oral squamous cell carcinoma via LncRNA-CAF/interleukin-33. Carcinogenesis 39:397-406. $10.1093 /$ carcin/bgy006

Esser J, Gehrmann U, D'Alexandri FL, Hidalgo-Estévez AM, Wheelock CE, Scheynius A, Gabrielsson S, and Rådmark O. 2010. Exosomes from human macrophages and dendritic cells contain enzymes for leukotriene biosynthesis and promote granulocyte migration. J Allergy Clin Immunol 126. 10.1016/j.jaci.2010.06.039

Falguières T, Castle D, and Gruenberg J. 2012. Regulation of the MVB pathway by SCAMP3. Traffic 13:131-142. 10.1111/j.1600-0854.2011.01291.x

Feng Y, Lv LL, Wu WJ, Li ZL, Chen J, Ni HF, Zhou LT, Tang TT, Wang FM, Wang B, Chen PS, Crowley SD, and Liu BC. 2018. Urinary Exosomes and Exosomal CCL2 mRNA as Biomarkers of Active Histologic Injury in IgA Nephropathy. Am J Pathol 188:2542-2552. 10.1016/j.ajpath.2018.07.017

Ferguson SW, and Nguyen J. 2016. Exosomes as therapeutics: The implications of molecular composition and exosomal heterogeneity. J Control Release 228:179-190. 10.1016/j.jconrel.2016.02.037

Fu M, Gu J, Jiang P, Qian H, Xu W, and Zhang X. 2019. Exosomes in gastric cancer: roles, mechanisms, and applications. Mol Cancer 18:41. 10.1186/s12943-019-1001-7

Fujiwara T, Eguchi T, Sogawa C, Ono K, Murakami J, Ibaragi S, Asaumi JI, Calderwood SK, Okamoto K, and Kozaki KI. 2018. Carcinogenic epithelial-mesenchymal transition initiated by oral cancer exosomes is inhibited by anti-EGFR antibody cetuximab. Oral Oncol 86:251-257. 10.1016/j.oraloncology.2018.09.030

Gardner A, and Ruffell B. 2016. Dendritic Cells and Cancer Immunity. Trends Immunol 37:855865. 10.1016/j.t. 2016.09.006

Gatto F, Schulze A, and Nielsen J. 2016. Systematic Analysis Reveals that Cancer Mutations Converge on Deregulated Metabolism of Arachidonate and Xenobiotics. Cell Rep 16:878-895. 10.1016/j.celrep.2016.06.038

Peer) reviewing PDF | (2020:06:49854:1:1:NEW 26 Aug 2020) 
703

704

705

706

707

708

709

710

711

712

713

714

715

716

717

718

719

720

721

722

723

724

725

726

727

728

729

730

731

732

733

734

735

736

737

738

739

740

741

742

743

744

745

746

747

748

749

750

751

752

753

Geis-Asteggiante L, Belew AT, Clements VK, Edwards NJ, Ostrand-Rosenberg S, El-Sayed NM, and Fenselau C. 2018. Differential Content of Proteins, mRNAs, and miRNAs Suggests that MDSC and Their Exosomes May Mediate Distinct Immune Suppressive Functions. J Proteome Res 17:486-498. 10.1021/acs.jproteome.7b00646

Gonzalez H, Robles I, and Werb Z. 2018. Innate and acquired immune surveillance in the postdissemination phase of metastasis. Febs j 285:654-664. 10.1111/febs.14325

Grant BD, and Donaldson JG. 2009. Pathways and mechanisms of endocytic recycling. Nat Rev Mol Cell Biol 10:597-608. 10.1038/nrm2755

Guenat D, Hermetet F, Prétet J-L, and Mougin C. 2017. Exosomes and Other Extracellular Vesicles in HPV Transmission and Carcinogenesis. Viruses 9. 10.3390/v9080211

Guo M, Wu F, Hu G, Chen L, Xu J, Xu P, Wang X, Li Y, Liu S, Zhang S, Huang Q, Fan J, Lv Z, Zhou M, Duan L, Liao T, Yang G, Tang K, Liu B, Liao X, Tao X, and Jin Y. 2019. Autologous tumor cell-derived microparticle-based targeted chemotherapy in lung cancer patients with malignant pleural effusion. Sci Transl Med 11. 10.1126/scitransImed.aat5690

Gupta B, Johnson NW, and Kumar N. 2016. Global Epidemiology of Head and Neck Cancers: A Continuing Challenge. Oncology 91:13-23. 10.1159/000446117

Gyorgy B, Szabo TG, Pasztoi M, Pal Z, Misjak P, Aradi B, Laszlo V, Pallinger E, Pap E, Kittel A, Nagy G, Falus A, and Buzas El. 2011. Membrane vesicles, current state-of-the-art: emerging role of extracellular vesicles. Cell Mol Life Sci 68:2667-2688. 10.1007/s00018011-0689-3

Hadavand M, and Hasni S. 2019. Exosomal biomarkers in oral diseases. Oral Dis 25:10-15. $10.1111 /$ odi. 12878

Han L, Cheng J, and Li A. 2020. hsa_circ_0072387 Suppresses Proliferation, Metastasis, and Glycolysis of Oral Squamous Cell Carcinoma Cells by Downregulating miR-503-5p. Cancer Biother Radiopharm. 10.1089/cbr.2019.3371

Hao YX, Li YM, Ye M, Guo YY, Li QW, Peng XM, Wang Q, Zhang SF, Zhao HX, Zhang H, Li $\mathrm{GH}$, Zhu JH, and Xiao WH. 2017. KRAS and BRAF mutations in serum exosomes from patients with colorectal cancer in a Chinese population. Oncol Lett 13:3608-3616. 10.3892/ol.2017.5889

Harada T, Yamamoto H, Kishida S, Kishida M, Awada C, Takao T, and Kikuchi A. 2017. Wnt5bassociated exosomes promote cancer cell migration and proliferation. Cancer Sci 108:42-52. 10.1111/cas.13109

Haraszti RA, Didiot MC, Sapp E, Leszyk J, Shaffer SA, Rockwell HE, Gao F, Narain NR, DiFiglia M, Kiebish MA, Aronin N, and Khvorova A. 2016. High-resolution proteomic and lipidomic analysis of exosomes and microvesicles from different cell sources. J Extracell Vesicles 5:32570. 10.3402/jev.v5.32570

He L, Ping F, Fan Z, Zhang C, Deng M, Cheng B, and Xia J. 2020. Salivary exosomal miR-24$3 p$ serves as a potential detective biomarker for oral squamous cell carcinoma screening. Biomed Pharmacother 121:109553. 10.1016/j.biopha.2019.109553

He T, Li X, Xie D, and Tian L. 2019. Overexpressed circPVT1 in oral squamous cell carcinoma promotes proliferation by serving as a miRNA sponge. Mol Med Rep 20:3509-3518. 10.3892/mmr.2019.10615

Hemler ME. 2003. Tetraspanin proteins mediate cellular penetration, invasion, and fusion events and define a novel type of membrane microdomain. Annu Rev Cell Dev Biol 19:397-422. 10.1146/annurev.cellbio.19.111301.153609

Hessvik NP, and Llorente A. 2018. Current knowledge on exosome biogenesis and release. Cell Mol Life Sci 75:193-208. 10.1007/s00018-017-2595-9

Higaki M, Shintani T, Hamada A, Rosli SNZ, and Okamoto T. 2020. Eldecalcitol (ED-71)induced exosomal miR-6887-5p suppresses squamous cell carcinoma cell growth by targeting heparin-binding protein 17/fibroblast growth factor-binding protein-1

Peer) reviewing PDF | (2020:06:49854:1:1:NEW 26 Aug 2020) 
754

755

756

757

758

759

760

761

762

763

764

765

766

767

768

769

770

771

772

773

774

775

776

777

778

779

780

781

782

783

784

785

786

787

788

789

790

791

792

793

794

795

796

797

798

799

800

801

802

803

804

(HBp17/FGFBP-1). In Vitro Cell Dev Biol Anim 56:222-233. 10.1007/s11626-020-00440$\mathrm{X}$

Hoshino A, Costa-Silva B, Shen TL, Rodrigues G, Hashimoto A, Tesic Mark M, Molina H, Kohsaka S, Di Giannatale A, Ceder S, Singh S, Williams C, Soplop N, Uryu K, Pharmer L, King T, Bojmar L, Davies AE, Ararso Y, Zhang T, Zhang H, Hernandez J, Weiss JM, Dumont-Cole VD, Kramer K, Wexler LH, Narendran A, Schwartz GK, Healey JH, Sandstrom P, Labori KJ, Kure EH, Grandgenett PM, Hollingsworth MA, de Sousa M, Kaur S, Jain M, Mallya K, Batra SK, Jarnagin WR, Brady MS, Fodstad O, Muller V, Pantel K, Minn AJ, Bissell MJ, Garcia BA, Kang Y, Rajasekhar VK, Ghajar CM, Matei I, Peinado H, Bromberg J, and Lyden D. 2015. Tumour exosome integrins determine organotropic metastasis. Nature 527:329-335. 10.1038/nature15756

Hu Q, Peng J, Chen X, Li H, Song M, Cheng B, and Wu T. 2019. Obesity and genes related to lipid metabolism predict poor survival in oral squamous cell carcinoma. Oral Oncol 89:14-22. 10.1016/j.oraloncology.2018.12.006

Huang X, Yuan T, Tschannen M, Sun Z, Jacob H, Du M, Liang M, Dittmar RL, Liu Y, Liang M, Kohli M, Thibodeau SN, Boardman L, and Wang L. 2013. Characterization of human plasma-derived exosomal RNAs by deep sequencing. BMC Genomics 14:319. 10.1186/1471-2164-14-319

Huotari J, and Helenius A. 2011. Endosome maturation. Embo j 30:3481-3500. 10.1038/emboj.2011.286

Jiang E, Xu Z, Wang M, Yan T, Huang C, Zhou X, Liu Q, Wang L, Chen Y, Wang H, Liu K, Shao $Z$, and Shang Z. 2019. Tumoral microvesicle-activated glycometabolic reprogramming in fibroblasts promotes the progression of oral squamous cell carcinoma. Faseb $j$ 33:56905703. 10.1096/fj.201802226R

Jin N, Jin N, Bu W, Li X, Liu L, Wang Z, Tong J, and Li D. 2020. Long non-coding RNA TIRY promotes tumor metastasis by enhancing epithelial-to-mesenchymal transition in oral cancer. Exp Biol Med (Maywood) 245:585-596. 10.1177/1535370220903673

Kadota T, Fujita Y, Yoshioka Y, Araya J, Kuwano K, and Ochiya T. 2016. Extracellular Vesicles in Chronic Obstructive Pulmonary Disease. Int J Mol Sci 17. 10.3390/ijms17111801

Kahlert C, Melo SA, Protopopov A, Tang J, Seth S, Koch M, Zhang J, Weitz J, Chin L, Futreal $A$, and Kalluri R. 2014. Identification of double-stranded genomic DNA spanning all chromosomes with mutated KRAS and p53 DNA in the serum exosomes of patients with pancreatic cancer. J Biol Chem 289:3869-3875. 10.1074/jbc.C113.532267

Kalluri R, and LeBleu VS. 2016. Discovery of Double-Stranded Genomic DNA in Circulating Exosomes. Cold Spring Harb Symp Quant Biol 81:275-280. 10.1101/sqb.2016.81.030932

Kawakubo-Yasukochi T, Morioka M, Hazekawa M, Yasukochi A, Nishinakagawa T, Ono K, Kawano S, Nakamura S, and Nakashima M. 2018. miR-200c-3p spreads invasive capacity in human oral squamous cell carcinoma microenvironment. Mol Carcinog 57:295-302. 10.1002/mc.22744

Ketabat F, Pundir M, Mohabatpour F, Lobanova L, Koutsopoulos S, Hadjiiski L, Chen X, Papagerakis P, and Papagerakis S. 2019. Controlled Drug Delivery Systems for Oral Cancer Treatment-Current Status and Future Perspectives. Pharmaceutics 11. 10.3390/pharmaceutics 11070302

Kim JW, Wieckowski E, Taylor DD, Reichert TE, Watkins S, and Whiteside TL. 2005. Fas ligand-positive membranous vesicles isolated from sera of patients with oral cancer induce apoptosis of activated T lymphocytes. Clin Cancer Res 11:1010-1020.

Kirave P, Gondaliya P, Kulkarni B, Rawal R, Garg R, Jain A, and Kalia K. 2020. Exosome mediated miR-155 delivery confers cisplatin chemoresistance in oral cancer cells via epithelial-mesenchymal transition. Oncotarget 11:1157-1171.

10.18632/oncotarget.27531

Peer] reviewing PDF | (2020:06:49854:1:1:NEW 26 Aug 2020) 
805

806

807

808

809

810

811

812

813

814

815

816

817

818

819

820

821

822

823

824

825

826

827

828

829

830

831

832

833

834

835

836

837

838

839

840

841

842

843

844

845

846

847

848

849

850

851

852

853

854

855

Kitai Y, Kawasaki T, Sueyoshi T, Kobiyama K, Ishii KJ, Zou J, Akira S, Matsuda T, and Kawai T. 2017. DNA-Containing Exosomes Derived from Cancer Cells Treated with Topotecan Activate a STING-Dependent Pathway and Reinforce Antitumor Immunity. J Immunol 198:1649-1659. 10.4049/jimmunol.1601694

Kulkarni B, Kirave P, Gondaliya P, Jash K, Jain A, Tekade RK, and Kalia K. 2019. Exosomal miRNA in chemoresistance, immune evasion, metastasis and progression of cancer. Drug Discov Today 24:2058-2067. 10.1016/j.drudis.2019.06.010

Lai YH, Liu H, Chiang WF, Chen TW, Chu LJ, Yu JS, Chen SJ, Chen HC, and Tan BC. 2018. MiR-31-5p-ACOX1 Axis Enhances Tumorigenic Fitness in Oral Squamous Cell Carcinoma Via the Promigratory Prostaglandin E2. Theranostics 8:486-504. 10.7150/thno.22059

Langevin S, Kuhnell D, Parry T, Biesiada J, Huang S, Wise-Draper T, Casper K, Zhang X, Medvedovic M, and Kasper S. 2017. Comprehensive microRNA-sequencing of exosomes derived from head and neck carcinoma cells in vitro reveals common secretion profiles and potential utility as salivary biomarkers. Oncotarget 8:82459-82474. 10.18632/oncotarget.19614

Languino LR, Singh A, Prisco M, Inman GJ, Luginbuhl A, Curry JM, and South AP. 2016. Exosome-mediated transfer from the tumor microenvironment increases TGF $\beta$ signaling in squamous cell carcinoma. Am J Transl Res 8:2432-2437.

Lázaro-Ibáñez E, Lunavat TR, Jang SC, Escobedo-Lucea C, Oliver-De La Cruz J, Siljander P, Lötvall J, and Yliperttula M. 2017. Distinct prostate cancer-related mRNA cargo in extracellular vesicle subsets from prostate cell lines. BMC cancer 17:92. 10.1186/s12885-017-3087-x

Li C, Zhou Y, Liu J, Su X, Qin H, Huang S, Huang X, and Zhou N. 2019a. Potential Markers from Serum-Purified Exosomes for Detecting Oral Squamous Cell Carcinoma Metastasis. Cancer Epidemiol Biomarkers Prev 28:1668-1681. 10.1158/1055-9965.EPI18-1122

Li J, Li Z, Jiang P, Peng M, Zhang X, Chen K, Liu H, Bi H, Liu X, and Li X. 2018a. Circular RNA IARS (circ-IARS) secreted by pancreatic cancer cells and located within exosomes regulates endothelial monolayer permeability to promote tumor metastasis. J Exp Clin Cancer Res 37:177. 10.1186/s13046-018-0822-3

Li L, Li C, Wang S, Wang Z, Jiang J, Wang W, Li X, Chen J, Liu K, Li C, and Zhu G. 2016. Exosomes Derived from Hypoxic Oral Squamous Cell Carcinoma Cells Deliver miR-21 to Normoxic Cells to Elicit a Prometastatic Phenotype. Cancer Res 76:1770-1780. 10.1158/0008-5472.can-15-1625

Li LM, Liu ZX, and Cheng QY. 2019b. Exosome plays an important role in the development of hepatocellular carcinoma. Pathol Res Pract 215:152468. 10.1016/j.prp.2019.152468

Li P, Kaslan M, Lee SH, Yao J, and Gao Z. 2017a. Progress in Exosome Isolation Techniques. Theranostics 7:789-804. 10.7150/thno.18133

Li W, Han Y, Zhao Z, Ji X, Wang X, Jin J, Wang Q, Guo X, Cheng Z, Lu M, Wang G, Wang Y, and Liu H. 2019c. Oral mucosal mesenchymal stem cellderived exosomes: A potential therapeutic target in oral premalignant lesions. Int $\mathrm{J}$ Oncol 54:1567-1578. 10.3892/ijo.2019.4756

Li W, Li C, Zhou T, Liu X, Liu X, Li X, and Chen D. 2017b. Role of exosomal proteins in cancer diagnosis. Mol Cancer 16:145. 10.1186/s12943-017-0706-8

Li X, Lei Y, Wu M, and Li N. 2018b. Regulation of Macrophage Activation and Polarization by HCC-Derived Exosomal IncRNA TUC339. Int J Mol Sci 19. 10.3390/ijms19102958

Li YY, Tao YW, Gao S, Li P, Zheng JM, Zhang SE, Liang J, and Zhang Y. 2018c. Cancerassociated fibroblasts contribute to oral cancer cells proliferation and metastasis via exosome-mediated paracrine miR-34a-5p. EBioMedicine 36:209-220.

10.1016/j.ebiom.2018.09.006

Peer) reviewing PDF | (2020:06:49854:1:1:NEW 26 Aug 2020) 
856

857

858

859

860

861

862

863

864

865

866

867

868

869

870

871

872

873

874

875

876

877

878

879

880

881

882

883

884

885

886

887

888

889

890

891

892

893

894

895

896

897

898

899

900

901

902

903

904

905

906

Liao W, Du Y, Zhang C, Pan F, Yao Y, Zhang T, and Peng Q. 2019. Exosomes: The next generation of endogenous nanomaterials for advanced drug delivery and therapy. Acta Biomater 86:1-14. 10.1016/j.actbio.2018.12.045

Lien MY, Tsai HC, Chang AC, Tsai MH, Hua CH, Wang SW, and Tang CH. 2018. Chemokine CCL4 Induces Vascular Endothelial Growth Factor C Expression and Lymphangiogenesis by miR-195-3p in Oral Squamous Cell Carcinoma. Front Immunol 9:412. 10.3389/fimmu.2018.00412

Lin K, Song LJ, Ma J, Zhang TS, You DY, and He YW. 2020. Identification of cancer hallmarkassociated gene and IncRNA cooperative regulation pairs and dictate IncRNA roles in oral squamous cell carcinoma. J Cell Mol Med 24:5213-5223. 10.1111/jcmm.15174

Linton SS, Abraham T, Liao J, Clawson GA, Butler PJ, Fox T, Kester M, and Matters GL. 2018. Tumor-promoting effects of pancreatic cancer cell exosomes on THP-1-derived macrophages. PLoS One 13:e0206759. 10.1371/journal.pone.0206759

Liu T, Chen G, Sun D, Lei M, Li Y, Zhou C, Li X, Xue W, Wang H, Liu C, and Xu J. 2017. Exosomes containing miR-21 transfer the characteristic of cisplatin resistance by targeting PTEN and PDCD4 in oral squamous cell carcinoma. Acta Biochim Biophys Sin (Shanghai) 49:808-816. 10.1093/abbs/gmx078

Llorente A, Skotland T, Sylvanne T, Kauhanen D, Rog T, Orlowski A, Vattulainen I, Ekroos K, and Sandvig K. 2013. Molecular lipidomics of exosomes released by PC-3 prostate cancer cells. Biochim Biophys Acta 1831:1302-1309. 10.1016/j.bbalip.2013.04.011

Ludwig N, Whiteside TL, and Reichert TE. 2019. Challenges in Exosome Isolation and Analysis in Health and Disease. Int J Mol Sci 20. 10.3390/ijms20194684

Ludwig N, Yerneni SS, Razzo BM, and Whiteside TL. 2018. Exosomes from HNSCC Promote Angiogenesis through Reprogramming of Endothelial Cells. Mol Cancer Res 16:17981808. 10.1158/1541-7786.Mcr-18-0358

Ludwig S, Floros T, Theodoraki MN, Hong CS, Jackson EK, Lang S, and Whiteside TL. 2017. Suppression of Lymphocyte Functions by Plasma Exosomes Correlates with Disease Activity in Patients with Head and Neck Cancer. Clin Cancer Res 23:4843-4854. 10.1158/1078-0432.ccr-16-2819

Luga V, Zhang L, Viloria-Petit AM, Ogunjimi AA, Inanlou MR, Chiu E, Buchanan M, Hosein AN, Basik M, and Wrana JL. 2012. Exosomes mediate stromal mobilization of autocrine WntPCP signaling in breast cancer cell migration. Cell 151:1542-1556. 10.1016/j.cell.2012.11.024

Lukic A, Wahlund CJE, Gómez C, Brodin D, Samuelsson B, Wheelock CE, Gabrielsson S, and Rådmark O. 2019. Exosomes and cells from lung cancer pleural exudates transform LTC4 to LTD4, promoting cell migration and survival via CysLT1. Cancer Lett 444:1-8. 10.1016/j.canlet.2018.11.033

Luo C, Sun J, Du Y, and He Z. 2014. Emerging integrated nanohybrid drug delivery systems to facilitate the intravenous-to-oral switch in cancer chemotherapy. $J$ Control Release 176:94-103. 10.1016/j.jconrel.2013.12.030

Malm T, Loppi S, and Kanninen KM. 2016. Exosomes in Alzheimer's disease. Neurochem Int 97:193-199. 10.1016/j.neuint.2016.04.011

Mantovani A, Marchesi F, Malesci A, Laghi L, and Allavena P. 2017. Tumour-associated macrophages as treatment targets in oncology. Nat Rev Clin Oncol 14:399-416. 10.1038/nrclinonc.2016.217

Mashouri L, Yousefi H, Aref AR, Ahadi AM, Molaei F, and Alahari SK. 2019. Exosomes: composition, biogenesis, and mechanisms in cancer metastasis and drug resistance. Mol Cancer 18:75. 10.1186/s12943-019-0991-5

Mata-Rocha M, Rodriguez-Hernandez RM, Chavez-Olmos P, Garrido E, Robles-Vazquez C, Aguilar-Ruiz S, Torres-Aguilar H, Gonzalez-Torres C, Gaytan-Cervantes J, MejiaArangure JM, and Romero-Tlalolini MLA. 2020. Presence of HPV DNA in extracellular

Peer] reviewing PDF | (2020:06:49854:1:1:NEW 26 Aug 2020) 
907

908

909

910

911

912

913

914

915

916

917

918

919

920

921

922

923

924

925

926

927

928

929

930

931

932

933

934

935

936

937

938

939

940

941

942

943

944

945

946

947

948

949

950

951

952

953

954

955

956 vesicles from HeLa cells and cervical samples. Enferm Infecc Microbiol Clin 38:159-165. 10.1016/j.eimc.2019.06.011

Matei I, Kim HS, and Lyden D. 2017. Unshielding Exosomal RNA Unleashes Tumor Growth And Metastasis. Cell 170:223-225. 10.1016/j.cell.2017.06.047

Mathieu M, Martin-Jaular L, Lavieu G, and Théry C. 2019. Specificities of secretion and uptake of exosomes and other extracellular vesicles for cell-to-cell communication. Nat Cell Biol 21:9-17. 10.1038/s41556-018-0250-9

McNally EK, and Brett CL. 2018. The intralumenal fragment pathway mediates ESCRTindependent surface transporter down-regulation. Nat Commun 9:5358.

10.1038/s41467-018-07734-5

Meckes DG, Jr., Shair KH, Marquitz AR, Kung CP, Edwards RH, and Raab-Traub N. 2010. Human tumor virus utilizes exosomes for intercellular communication. Proc Natl Acad Sci U S A 107:20370-20375. 10.1073/pnas.1014194107

Melo SA, Luecke LB, Kahlert C, Fernandez AF, Gammon ST, Kaye J, LeBleu VS, Mittendorf EA, Weitz J, Rahbari N, Reissfelder C, Pilarsky C, Fraga MF, Piwnica-Worms D, and Kalluri R. 2015. Glypican-1 identifies cancer exosomes and detects early pancreatic cancer. Nature 523:177-182. 10.1038/nature14581

Miki Y, Yashiro M, Okuno T, Kuroda K, Togano S, Hirakawa K, and Ohira M. 2018. Clinicopathological significance of exosome marker CD63 expression on cancer cells and stromal cells in gastric cancer. PLoS One 13:e0202956. 10.1371/journal.pone.0202956

Milman N, Ginini L, and Gil Z. 2019. Exosomes and their role in tumorigenesis and anticancer drug resistance. Drug Resist Updat 45:1-12. 10.1016/j.drup.2019.07.003

Momen-Heravi F, and Bala S. 2018. Extracellular vesicles in oral squamous carcinoma carry oncogenic miRNA profile and reprogram monocytes via NF-kappaB pathway. Oncotarget 9:34838-34854. 10.18632/oncotarget.26208

Morelli AE, Larregina AT, Shufesky WJ, Sullivan ML, Stolz DB, Papworth GD, Zahorchak AF, Logar AJ, Wang Z, Watkins SC, Falo LD, Jr., and Thomson AW. 2004. Endocytosis, intracellular sorting, and processing of exosomes by dendritic cells. Blood 104:32573266. 10.1182/blood-2004-03-0824

Morris KV, and Mattick JS. 2014. The rise of regulatory RNA. Nat Rev Genet 15:423-437. $10.1038 / \mathrm{nrg} 3722$

Murphy DE, de Jong OG, Brouwer M, Wood MJ, Lavieu G, Schiffelers RM, and Vader P. 2019. Extracellular vesicle-based therapeutics: natural versus engineered targeting and trafficking. Exp Mol Med 51:1-12. 10.1038/s12276-019-0223-5

Nakamura H, Tamaki S, Yagyuu T, Yamakawa N, Hatake K, and Kirita T. 2019. Relationship Between EGFR Expression in Oral Cancer Cell Lines and Cetuximab Antibodydependent Cell-mediated Cytotoxicity. Anticancer Res 39:1275-1282. 10.21873/anticanres.13238

Nasry WHS, Rodriguez-Lecompte JC, and Martin CK. 2018. Role of COX-2/PGE2 Mediated Inflammation in Oral Squamous Cell Carcinoma. Cancers (Basel) 10. 10.3390/cancers 10100348

Natsuizaka M, Whelan KA, Kagawa S, Tanaka K, Giroux V, Chandramouleeswaran PM, Long A, Sahu V, Darling DS, Que J, Yang Y, Katz JP, Wileyto EP, Basu D, Kita Y, Natsugoe S, Naganuma S, Klein-Szanto AJ, Diehl JA, Bass AJ, Wong KK, Rustgi AK, and Nakagawa H. 2017. Interplay between Notch1 and Notch3 promotes EMT and tumor initiation in squamous cell carcinoma. Nat Commun 8:1758. 10.1038/s41467-017-015009

Oliveira-Silva RJ, Carolina de Carvalho A, de Souza Viana L, Carvalho AL, and Reis RM. 2016. Anti-EGFR Therapy: Strategies in Head and Neck Squamous Cell Carcinoma. Recent Pat Anticancer Drug Discov 11:170-183. 10.2174/1574892811666160309121238 
957

958

959

960

961

962

963

964

965

966

967

968

969

970

971

972

973

974

975

976

977

978

979

980

981

982

983

984

985

986

987

988

989

990

991

992

993

994

995

996

997

998

999

1000

1001

1002

1003

1004

1005

Ono K, Eguchi T, Sogawa C, Calderwood SK, Futagawa J, Kasai T, Seno M, Okamoto K, Sasaki A, and Kozaki K-I. 2018. HSP-enriched properties of extracellular vesicles involve survival of metastatic oral cancer cells. J Cell Biochem 119:7350-7362. $10.1002 / j \mathrm{jcb} .27039$

Overmiller AM, Pierluissi JA, Wermuth PJ, Sauma S, Martinez-Outschoorn U, Tuluc M, Luginbuhl A, Curry J, Harshyne LA, Wahl JK, 3rd, South AP, and Mahoney MG. 2017. Desmoglein 2 modulates extracellular vesicle release from squamous cell carcinoma keratinocytes. Faseb j 31:3412-3424. 10.1096/fj.201601138RR

Pakravan K, Babashah S, Sadeghizadeh M, Mowla SJ, Mossahebi-Mohammadi M, Ataei F, Dana N, and Javan M. 2017. MicroRNA-100 shuttled by mesenchymal stem cell-derived exosomes suppresses in vitro angiogenesis through modulating the mTOR/HIF1alpha/VEGF signaling axis in breast cancer cells. Cell Oncol (Dordr) 40:457-470. 10.1007/s13402-017-0335-7

Pascual G, Avgustinova A, Mejetta S, Martin M, Castellanos A, Attolini CS, Berenguer A, Prats N, Toll A, Hueto JA, Bescos C, Di Croce L, and Benitah SA. 2017. Targeting metastasisinitiating cells through the fatty acid receptor CD36. Nature 541:41-45. 10.1038/nature20791

Pasquier J, Guerrouahen BS, Al Thawadi H, Ghiabi P, Maleki M, Abu-Kaoud N, Jacob A, Mirshahi M, Galas L, Rafii S, Le Foll F, and Rafii A. 2013. Preferential transfer of mitochondria from endothelial to cancer cells through tunneling nanotubes modulates chemoresistance. J Transl Med 11:94. 10.1186/1479-5876-11-94

Poonia M, Ramalingam K, Goyal S, and Sidhu SK. 2017. Nanotechnology in oral cancer: A comprehensive review. J Oral Maxillofac Pathol 21:407-414. 10.4103/jomfp.JOMFP_29_17

Principe S, Mejia-Guerrero S, Ignatchenko V, Sinha A, Ignatchenko A, Shi W, Pereira K, Su S, Huang SH, O'Sullivan B, Xu W, Goldstein DP, Weinreb I, Ailles L, Liu FF, and Kislinger T. 2018. Proteomic Analysis of Cancer-Associated Fibroblasts Reveals a Paracrine Role for MFAP5 in Human Oral Tongue Squamous Cell Carcinoma. J Proteome Res 17:2045-2059. 10.1021/acs.jproteome.7b00925

Qadir F, Aziz MA, Sari CP, Ma H, Dai H, Wang X, Raithatha D, Da Silva LGL, Hussain M, Poorkasreiy SP, Hutchison IL, Waseem A, and Teh MT. 2018. Transcriptome reprogramming by cancer exosomes: identification of novel molecular targets in matrix and immune modulation. Mol Cancer 17:97. 10.1186/s12943-018-0846-5

Qin X, Guo H, Wang X, Zhu X, Yan M, Wang X, Xu Q, Shi J, Lu E, Chen W, and Zhang J. 2019. Exosomal miR-196a derived from cancer-associated fibroblasts confers cisplatin resistance in head and neck cancer through targeting CDKN1B and ING5. Genome Biol 20:12. 10.1186/s13059-018-1604-0

Qiu X, Ke X, Ma H, Han L, Chen Q, Zhang S, Da P, and Wu H. 2019. Profiling and bioinformatics analyses reveal differential expression of circular RNA in tongue cancer revealed by high-throughput sequencing. $J$ Cell Biochem 120:4102-4112. $10.1002 / j c b .27695$

Rabinowits G, Bowden M, Flores LM, Verselis S, Vergara V, Jo VY, Chau N, Lorch J, Hammerman PS, Thomas T, Goguen LA, Annino D, Schoenfeld JD, Margalit DN, Tishler RB, and Haddad RI. 2017. Comparative Analysis of MicroRNA Expression among Benign and Malignant Tongue Tissue and Plasma of Patients with Tongue Cancer. Front Oncol 7:191. 10.3389/fonc.2017.00191

Razzo BM, Ludwig N, Hong CS, Sharma P, Fabian KP, Fecek RJ, Storkus WJ, and Whiteside TL. 2019. Tumor-derived exosomes promote carcinogenesis of murine oral squamous cell carcinoma. Carcinogenesis. 10.1093/carcin/bgz124

Peer] reviewing PDF | (2020:06:49854:1:1:NEW 26 Aug 2020) 
1006

1007

1008

1009

1010

1011

1012

1013

1014

1015

1016

1017

1018

1019

1020

1021

1022

1023

1024

1025

1026

1027

1028

1029

1030

1031

1032

1033

1034

1035

1036

1037

1038

1039

1040

1041

1042

1043

1044

1045

1046

1047

1048

1049

1050

1051

1052

1053

1054

1055

1056

Record M, Carayon K, Poirot M, and Silvente-Poirot S. 2014. Exosomes as new vesicular lipid transporters involved in cell-cell communication and various pathophysiologies. Biochim Biophys Acta 1841:108-120. 10.1016/j.bbalip.2013.10.004

Record M, Silvente-Poirot S, Poirot M, and Wakelam MJO. 2018. Extracellular vesicles: lipids as key components of their biogenesis and functions. J Lipid Res 59:1316-1324. 10.1194/jIr.E086173

Ren J, Ding L, Zhang D, Shi G, Xu Q, Shen S, Wang Y, Wang T, and Hou Y. 2018. Carcinomaassociated fibroblasts promote the stemness and chemoresistance of colorectal cancer by transferring exosomal IncRNA H19. Theranostics 8:3932-3948. 10.7150/thno.25541

Rodríguez Zorrilla S, Pérez-Sayans M, Fais S, Logozzi M, Gallas Torreira M, and García García A. 2019. A Pilot Clinical Study on the Prognostic Relevance of Plasmatic Exosomes Levels in Oral Squamous Cell Carcinoma Patients. Cancers (Basel) 11. $10.3390 /$ cancers 11030429

Romano G, Veneziano D, Acunzo M, and Croce CM. 2017. Small non-coding RNA and cancer. Carcinogenesis 38:485-491. 10.1093/carcin/bgx026

Sakha S, Muramatsu T, Ueda K, and Inazawa J. 2016. Exosomal microRNA miR-1246 induces cell motility and invasion through the regulation of DENND2D in oral squamous cell carcinoma. Sci Rep 6:38750. 10.1038/srep38750

San Lucas FA, Allenson K, Bernard V, Castillo J, Kim DU, Ellis K, Ehli EA, Davies GE, Petersen JL, Li D, Wolff R, Katz M, Varadhachary G, Wistuba I, Maitra A, and Alvarez H. 2016. Minimally invasive genomic and transcriptomic profiling of visceral cancers by nextgeneration sequencing of circulating exosomes. Ann Oncol 27:635-641. 10.1093/annonc/mdv604

Sanada T, Islam A, Kaminota T, Kirino Y, Tanimoto R, Yoshimitsu H, Yano H, Mizuno Y, Okada M, Mitani S, Ugumori T, Tanaka J, and Hato N. 2020. Elevated exosomal lysyl oxidase like 2 is a potential biomarker for head and neck squamous cell carcinoma. Laryngoscope 130:E327-e334. 10.1002/lary.28142

Shah R, Patel T, and Freedman JE. 2018. Circulating Extracellular Vesicles in Human Disease. N Engl J Med 379:958-966. 10.1056/NEJMra1704286

Shao H, Im H, Castro CM, Breakefield X, Weissleder R, and Lee H. 2018. New Technologies for Analysis of Extracellular Vesicles. Chem Rev 118:1917-1950. 10.1021/acs.chemrev.7b00534

Sharma S, Gillespie BM, Palanisamy V, and Gimzewski JK. 2011. Quantitative nanostructural and single-molecule force spectroscopy biomolecular analysis of human-saliva-derived exosomes. Langmuir : the ACS journal of surfaces and colloids 27:14394-14400. 10.1021/la2038763

Shigetomi S, Imanishi Y, Shibata K, Sakai N, Sakamoto K, Fujii R, Habu N, Otsuka K, Sato Y, Watanabe Y, Shimoda M, Kameyama K, Ozawa H, Tomita T, and Ogawa K. 2018. VEGF-C/FIt-4 axis in tumor cells contributes to the progression of oral squamous cell carcinoma via upregulating VEGF-C itself and contactin-1 in an autocrine manner. Am J Cancer Res 8:2046-2063.

Shostak K, and Chariot A. 2015. EGFR and NF-KB: partners in cancer. Trends Mol Med 21:385393. 10.1016/j.molmed.2015.04.001

Sigismund S, Avanzato D, and Lanzetti L. 2018. Emerging functions of the EGFR in cancer. Mol Oncol 12:3-20. 10.1002/1878-0261.12155

Skog J, Wurdinger T, van Rijn S, Meijer DH, Gainche L, Sena-Esteves M, Curry WT, Jr., Carter BS, Krichevsky AM, and Breakefield XO. 2008. Glioblastoma microvesicles transport RNA and proteins that promote tumour growth and provide diagnostic biomarkers. Nat Cell Biol 10:1470-1476. 10.1038/ncb1800

Subra C, Grand D, Laulagnier K, Stella A, Lambeau G, Paillasse M, De Medina P, Monsarrat B, Perret B, Silvente-Poirot S, Poirot M, and Record M. 2010. Exosomes account for

Peer) reviewing PDF | (2020:06:49854:1:1:NEW 26 Aug 2020) 
1057

1058

1059

1060

1061

1062

1063

1064

1065

1066

1067

1068

1069

1070

1071

1072

1073

1074

1075

1076

1077

1078

1079

1080

1081

1082

1083

1084

1085

1086

1087

1088

1089

1090

1091

1092

1093

1094

1095

1096

1097

1098

1099

1100

1101

1102

1103

1104

1105

1106

1107

vesicle-mediated transcellular transport of activatable phospholipases and prostaglandins. J Lipid Res 51:2105-2120. 10.1194/jr.M003657

Subra C, Laulagnier K, Perret B, and Record M. 2007. Exosome lipidomics unravels lipid sorting at the level of multivesicular bodies. Biochimie 89:205-212. 10.1016/j.biochi.2006.10.014

Sun D, Zhuang X, Xiang X, Liu Y, Zhang S, Liu C, Barnes S, Grizzle W, Miller D, and Zhang HG. 2010. A novel nanoparticle drug delivery system: the anti-inflammatory activity of curcumin is enhanced when encapsulated in exosomes. Mol Ther 18:1606-1614. $10.1038 / \mathrm{mt} .2010 .105$

Sun LP, Xu K, Cui J, Yuan DY, Zou B, Li J, Liu JL, Li KY, Meng Z, and Zhang B. 2019. Cancer-associated fibroblast-derived exosomal miR-382-5p promotes the migration and invasion of oral squamous cell carcinoma. Oncol Rep 42:1319-1328. 10.3892/or.2019.7255

Surman M, Drożdż A, Stępień E, and Przybyło M. 2019. Extracellular Vesicles as Drug Delivery Systems - Methods of Production and Potential Therapeutic Applications. Curr Pharm Des 25:132-154. 10.2174/1381612825666190306153318

Svoronos AA, Engelman DM, and Slack FJ. 2016. OncomiR or Tumor Suppressor? The Duplicity of MicroRNAs in Cancer. Cancer Res 76:3666-3670. 10.1158/0008-5472.can16-0359

Tan J, Xiang L, and Xu G. 2019. LncRNA MEG3 suppresses migration and promotes apoptosis by sponging miR-548d-3p to modulate JAK-STAT pathway in oral squamous cell carcinoma. IUBMB Life 71:882-890. 10.1002/iub.2012

Teng MW, Galon J, Fridman WH, and Smyth MJ. 2015. From mice to humans: developments in cancer immunoediting. J Clin Invest 125:3338-3346. 10.1172/jci80004

Théry C, Witwer KW, Aikawa E, Alcaraz MJ, Anderson JD, Andriantsitohaina R, Antoniou A, Arab T, Archer F, Atkin-Smith GK, Ayre DC, Bach JM, Bachurski D, Baharvand H, Balaj L, Baldacchino S, Bauer NN, Baxter AA, Bebawy M, Beckham C, Bedina Zavec A, Benmoussa A, Berardi AC, Bergese P, Bielska E, Blenkiron C, Bobis-Wozowicz S, Boilard E, Boireau W, Bongiovanni A, Borràs FE, Bosch S, Boulanger CM, Breakefield X, Breglio AM, Brennan M, Brigstock DR, Brisson A, Broekman ML, Bromberg JF, BrylGórecka P, Buch S, Buck AH, Burger D, Busatto S, Buschmann D, Bussolati B, Buzás El, Byrd JB, Camussi G, Carter DR, Caruso S, Chamley LW, Chang YT, Chen C, Chen $S$, Cheng L, Chin AR, Clayton A, Clerici SP, Cocks A, Cocucci E, Coffey RJ, Cordeiroda-Silva A, Couch Y, Coumans FA, Coyle B, Crescitelli R, Criado MF, D'Souza-Schorey C, Das S, Datta Chaudhuri A, de Candia P, De Santana EF, De Wever O, Del Portillo HA, Demaret T, Deville S, Devitt A, Dhondt B, Di Vizio D, Dieterich LC, Dolo V, Dominguez Rubio AP, Dominici M, Dourado MR, Driedonks TA, Duarte FV, Duncan HM, Eichenberger RM, Ekström K, El Andaloussi S, Elie-Caille C, Erdbrügger U, FalcónPérez JM, Fatima F, Fish JE, Flores-Bellver M, Försönits A, Frelet-Barrand A, Fricke F, Fuhrmann G, Gabrielsson S, Gámez-Valero A, Gardiner C, Gärtner K, Gaudin R, Gho YS, Giebel B, Gilbert C, Gimona M, Giusti I, Goberdhan DC, Görgens A, Gorski SM, Greening DW, Gross JC, Gualerzi A, Gupta GN, Gustafson D, Handberg A, Haraszti RA, Harrison P, Hegyesi H, Hendrix A, Hill AF, Hochberg FH, Hoffmann KF, Holder B, Holthofer H, Hosseinkhani B, Hu G, Huang Y, Huber V, Hunt S, Ibrahim AG, Ikezu T, Inal JM, Isin M, Ivanova A, Jackson HK, Jacobsen S, Jay SM, Jayachandran M, Jenster G, Jiang L, Johnson SM, Jones JC, Jong A, Jovanovic-Talisman T, Jung S, Kalluri R, Kano SI, Kaur S, Kawamura Y, Keller ET, Khamari D, Khomyakova E, Khvorova A, Kierulf P, Kim KP, Kislinger T, Klingeborn M, Klinke DJ, 2nd, Kornek M, Kosanović MM, Kovács Á F, Krämer-Albers EM, Krasemann S, Krause M, Kurochkin IV, Kusuma GD, Kuypers S, Laitinen S, Langevin SM, Languino LR, Lannigan J, Lässer C, Laurent LC, Lavieu G, Lázaro-lbáñez E, Le Lay S, Lee MS, Lee YXF, Lemos DS, Lenassi M, Leszczynska A, Li IT, Liao K, Libregts SF, Ligeti E, Lim R, Lim SK, Linē A,

Peer) reviewing PDF | (2020:06:49854:1:1:NEW 26 Aug 2020) 
1108

1109

1110

1111

1112

1113

1114

1115

1116

1117

1118

1119

1120

1121

1122

1123

1124

1125

1126

1127

1128

1129

1130

1131

1132

1133

1134

1135

1136

1137

1138

1139

1140

1141

1142

1143

1144

1145

1146

1147

1148

1149

1150

1151

1152

1153

1154

1155

1156

1157
Linnemannstöns K, Llorente A, Lombard CA, Lorenowicz MJ, Lörincz Á M, Lötvall J, Lovett J, Lowry MC, Loyer X, Lu Q, Lukomska B, Lunavat TR, Maas SL, Malhi H, Marcilla A, Mariani J, Mariscal J, Martens-Uzunova ES, Martin-Jaular L, Martinez MC, Martins VR, Mathieu M, Mathivanan S, Maugeri M, McGinnis LK, McVey MJ, Meckes DG, Jr., Meehan KL, Mertens I, Minciacchi VR, Möller A, Møller Jørgensen M, MoralesKastresana A, Morhayim J, Mullier F, Muraca M, Musante L, Mussack V, Muth DC, Myburgh KH, Najrana T, Nawaz M, Nazarenko I, Nejsum P, Neri C, Neri T, Nieuwland R, Nimrichter L, Nolan JP, Nolte-'t Hoen EN, Noren Hooten N, O'Driscoll L, O'Grady T, O'Loghlen A, Ochiya T, Olivier M, Ortiz A, Ortiz LA, Osteikoetxea X, Østergaard O, Ostrowski M, Park J, Pegtel DM, Peinado H, Perut F, Pfaffl MW, Phinney DG, Pieters BC, Pink RC, Pisetsky DS, Pogge von Strandmann E, Polakovicova I, Poon IK, Powell BH, Prada I, Pulliam L, Quesenberry P, Radeghieri A, Raffai RL, Raimondo S, Rak J, Ramirez MI, Raposo G, Rayyan MS, Regev-Rudzki N, Ricklefs FL, Robbins PD, Roberts DD, Rodrigues SC, Rohde E, Rome S, Rouschop KM, Rughetti A, Russell AE, Saá P, Sahoo S, Salas-Huenuleo E, Sánchez C, Saugstad JA, Saul MJ, Schiffelers RM, Schneider R, Schøyen TH, Scott A, Shahaj E, Sharma S, Shatnyeva O, Shekari F, Shelke GV, Shetty AK, Shiba K, Siljander PR, Silva AM, Skowronek A, Snyder OL, 2nd, Soares RP, Sódar BW, Soekmadji C, Sotillo J, Stahl PD, Stoorvogel W, Stott SL, Strasser EF, Swift S, Tahara H, Tewari M, Timms K, Tiwari S, Tixeira R, Tkach M, Toh WS, Tomasini R, Torrecilhas AC, Tosar JP, Toxavidis V, Urbanelli L, Vader P, van Balkom BW, van der Grein SG, Van Deun J, van Herwijnen MJ, Van Keuren-Jensen K, van Niel G, van Royen ME, van Wijnen AJ, Vasconcelos MH, Vechetti IJ, Jr., Veit TD, Vella LJ, Velot É, Verweij FJ, Vestad B, Viñas JL, Visnovitz T, Vukman KV, Wahlgren J, Watson DC, Wauben MH, Weaver A, Webber JP, Weber V, Wehman AM, Weiss DJ, Welsh JA, Wendt S, Wheelock AM, Wiener Z, Witte L, Wolfram J, Xagorari A, Xander P, Xu J, Yan X, Yáñez-Mó M, Yin H, Yuana Y, Zappulli V, Zarubova J, Žèkas V, Zhang JY, Zhao Z, Zheng L, Zheutlin AR, Zickler AM, Zimmermann P, Zivkovic AM, Zocco D, and Zuba-Surma EK. 2018. Minimal information for studies of extracellular vesicles 2018 (MISEV2018): a position statement of the International Society for Extracellular Vesicles and update of the MISEV2014 guidelines. J Extracell Vesicles 7:1535750. 10.1080/20013078.2018.1535750

Tian Y, Li S, Song J, Ji T, Zhu M, Anderson GJ, Wei J, and Nie G. 2014. A doxorubicin delivery platform using engineered natural membrane vesicle exosomes for targeted tumor therapy. Biomaterials 35:2383-2390. 10.1016/j.biomaterials.2013.11.083

Tkach M, and Théry C. 2016. Communication by Extracellular Vesicles: Where We Are and Where We Need to Go. Cell 164:1226-1232. 10.1016/j.cell.2016.01.043

Tousignant KD, Rockstroh A, Taherian Fard A, Lehman ML, Wang C, McPherson SJ, Philp LK, Bartonicek N, Dinger ME, Nelson CC, and Sadowski MC. 2019. Lipid Uptake Is an Androgen-Enhanced Lipid Supply Pathway Associated with Prostate Cancer Disease Progression and Bone Metastasis. Mol Cancer Res 17:1166-1179. 10.1158/15417786.Mcr-18-1147

Trajkovic K, Hsu C, Chiantia S, Rajendran L, Wenzel D, Wieland F, Schwille P, Brugger B, and Simons M. 2008. Ceramide triggers budding of exosome vesicles into multivesicular endosomes. Science 319:1244-1247. 10.1126/science.1153124

Uzawa K, Kasamatsu A, Baba T, Kimura Y, Nakashima D, Higo M, Sakamoto Y, Ogawara K, Shiiba M, and Tanzawa H. 2015. Quantitative detection of circulating tumor-derived mitochondrial NADH subunit variants as a potential prognostic biomarker for oral cancer. Int J Oncol 47:1077-1083. 10.3892/ijo.2015.3083

Vader P, Mol EA, Pasterkamp G, and Schiffelers RM. 2016. Extracellular vesicles for drug delivery. Adv Drug Deliv Rev 106:148-156. 10.1016/j.addr.2016.02.006 
1158

1159

1160

1161

1162

1163

1164

1165

1166

1167

1168

1169

1170

1171

1172

1173

1174

1175

1176

1177

1178

1179

1180

1181

1182

1183

1184

1185

1186

1187

1188

1189

1190

1191

1192

1193

1194

1195

1196

1197

1198

1199

1200

1201

1202

1203

1204

1205

1206

1207

1208

Valadi H, Ekstrom K, Bossios A, Sjostrand M, Lee JJ, and Lotvall JO. 2007. Exosome-mediated transfer of mRNAs and microRNAs is a novel mechanism of genetic exchange between cells. Nat Cell Biol 9:654-659. 10.1038/ncb1596

van Niel G, D'Angelo G, and Raposo G. 2018. Shedding light on the cell biology of extracellular vesicles. Nat Rev Mol Cell Biol 19:213-228. 10.1038/nrm.2017.125

van Niel G, Porto-Carreiro I, Simoes S, and Raposo G. 2006. Exosomes: a common pathway for a specialized function. J Biochem 140:13-21. 10.1093/jb/mvj128

Wang J, Zhou Y, Lu J, Sun Y, Xiao H, Liu M, and Tian L. 2014. Combined detection of serum exosomal miR-21 and HOTAIR as diagnostic and prognostic biomarkers for laryngeal squamous cell carcinoma. Med Oncol 31:148. 10.1007/s12032-014-0148-8

Wang L, Li Y, Guan X, Zhao J, Shen L, and Liu J. 2018a. Exosomal double-stranded DNA as a biomarker for the diagnosis and preoperative assessment of pheochromocytoma and paraganglioma. Mol Cancer 17:128. 10.1186/s12943-018-0876-z

Wang S-H, Liou G-G, Liu S-H, Chang JS, Hsiao J-R, Yen Y-C, Chen Y-L, Wu W-L, Chang J-Y, and Chen Y-W. 2019a. Laminin y2-enriched extracellular vesicles of oral squamous cell carcinoma cells enhance in vitro lymphangiogenesis via integrin a3-dependent uptake by lymphatic endothelial cells. International journal of cancer 144:2795-2810. $10.1002 /$ ijc. 32027

Wang X, Li H, and Shi J. 2019b. LncRNA HOXA11-AS Promotes Proliferation and Cisplatin Resistance of Oral Squamous Cell Carcinoma by Suppression of miR-214-3p Expression. Biomed Res Int 2019:8645153. 10.1155/2019/8645153

Wang X, Qin X, Yan M, Shi J, Xu Q, Li Z, Yang W, Zhang J, and Chen W. 2019c. Loss of exosomal miR-3188 in cancer-associated fibroblasts contributes to HNC progression. $J$ Exp Clin Cancer Res 38:151. 10.1186/s13046-019-1144-9

Wang Y, Qin X, Zhu X, Chen W, Zhang J, and Chen W. 2018b. Oral cancer-derived exosomal NAP1 enhances cytotoxicity of natural killer cells via the IRF-3 pathway. Oral Oncol 76:34-41. 10.1016/j.oraloncology.2017.11.024

Wei T, Ye P, Yu GY, and Zhang ZY. 2020. Circular RNA expression profiling identifies specific circular RNAs in tongue squamous cell carcinoma. Mol Med Rep 21:1727-1738. 10.3892/mmr.2020.10980

Xiao M, Zhang J, Chen W, and Chen W. 2018. M1-like tumor-associated macrophages activated by exosome-transferred THBS1 promote malignant migration in oral squamous cell carcinoma. J Exp Clin Cancer Res 37:143. 10.1186/s13046-018-0815-2

Xie C, Du LY, Guo F, Li X, and Cheng B. 2019. Exosomes derived from microRNA-101-3poverexpressing human bone marrow mesenchymal stem cells suppress oral cancer cell proliferation, invasion, and migration. Mol Cell Biochem 458:11-26. 10.1007/s11010-01903526-7

Xiong HG, Li H, Xiao Y, Yang QC, Yang LL, Chen L, Bu LL, Zhang WF, Zhang JL, and Sun ZJ. 2019. Long noncoding RNA MYOSLID promotes invasion and metastasis by modulating the partial epithelial-mesenchymal transition program in head and neck squamous cell carcinoma. J Exp Clin Cancer Res 38:278. 10.1186/s13046-019-1254-4

Xu D, Chen Y, Yuan C, Zhang S, and Peng W. 2019. Long non-coding RNA LINC00662 promotes proliferation and migration in oral squamous cell carcinoma. Onco Targets Ther 12:647-656. 10.2147/ott.S188691

Xue M, Chen W, Xiang A, Wang R, Chen H, Pan J, Pang H, An H, Wang X, Hou H, and Li X. 2017. Hypoxic exosomes facilitate bladder tumor growth and development through transferring long non-coding RNA-UCA1. Mol Cancer 16:143. 10.1186/s12943-0170714-8

Yakob M, Fuentes L, Wang MB, Abemayor E, and Wong DT. 2014. Salivary biomarkers for detection of oral squamous cell carcinoma - current state and recent advances. Curr Oral Health Rep 1:133-141. 10.1007/s40496-014-0014-y

Peer) reviewing PDF | (2020:06:49854:1:1:NEW 26 Aug 2020) 
1209

1210

1211

1212

1213

1214

1215

1216

1217

1218

1219

1220

1221

1222

1223

1224

1225

1226

1227

1228

1229

1230

1231

1232

1233

1234

1235

1236

1237

1238

1239

1240

1241

1242

1243

1244

1245

1246

1247

1248

1249

1250

1251

1252

1253

1254

1255

1256

1257

1258

1259

Yang CC, and Chang KW. 2018. Eicosanoids and HB-EGF/EGFR in cancer. Cancer Metastasis Rev 37:385-395. 10.1007/s10555-018-9746-9

Yang M, and Wu SY. 2018. The Advances and Challenges in Utilizing Exosomes for Delivering Cancer Therapeutics. Front Pharmacol 9:735. 10.3389/fphar.2018.00735

Yang S, Che SP, Kurywchak P, Tavormina JL, Gansmo LB, Correa de Sampaio P, Tachezy M, Bockhorn M, Gebauer F, Haltom AR, Melo SA, LeBleu VS, and Kalluri R. 2017a.

Detection of mutant KRAS and TP53 DNA in circulating exosomes from healthy individuals and patients with pancreatic cancer. Cancer Biol Ther 18:158-165. $10.1080 / 15384047.2017 .1281499$

Yang Y, Han Q, Hou Z, Zhang C, Tian Z, and Zhang J. 2017b. Exosomes mediate hepatitis B virus (HBV) transmission and NK-cell dysfunction. Cell Mol Immunol 14:465-475. 10.1038/cmi.2016.24

Yang Y, Wen L, and Zhu H. 2015. Unveiling the hidden function of long non-coding RNA by identifying its major partner-protein. Cell Biosci 5:59. 10.1186/s13578-015-0050-x

Zeng Z, Li Y, Pan Y, Lan X, Song F, Sun J, Zhou K, Liu X, Ren X, Wang F, Hu J, Zhu X, Yang W, Liao W, Li G, Ding Y, and Liang L. 2018. Cancer-derived exosomal miR-25-3p promotes pre-metastatic niche formation by inducing vascular permeability and angiogenesis. Nat Commun 9:5395. 10.1038/s41467-018-07810-w

Zhan C, Yang X, Yin X, and Hou J. 2019. Exosomes and other extracellular vesicles in oral and salivary gland cancers. Oral Dis. 10.1111/odi.13172

Zhang H, Zeitz MJ, Wang H, Niu B, Ge S, Li W, Cui J, Wang G, Qian G, Higgins MJ, Fan X, Hoffman AR, and Hu JF. 2014. Long noncoding RNA-mediated intrachromosomal interactions promote imprinting at the Kcnq1 locus. J Cell Biol 204:61-75. $10.1083 / j c b .201304152$

Zhang H, Zhu L, Bai M, Liu Y, Zhan Y, Deng T, Yang H, Sun W, Wang X, Zhu K, Fan Q, Li J, Ying G, and Ba Y. 2019a. Exosomal circRNA derived from gastric tumor promotes white adipose browning by targeting the miR-133/PRDM16 pathway. International journal of cancer 144:2501-2515. 10.1002/ijc.31977

Zhang J, Li S, Li L, Li M, Guo C, Yao J, and Mi S. 2015. Exosome and exosomal microRNA: trafficking, sorting, and function. Genomics Proteomics Bioinformatics 13:17-24. 10.1016/j.gpb.2015.02.001

Zhang M, Han N, Jiang Y, Wang J, Li G, Lv X, Li G, and Qiao Q. 2018. EGFR confers radioresistance in human oropharyngeal carcinoma by activating endoplasmic reticulum stress signaling PERK-elF2 $\alpha-G R P 94$ and IRE1 $\alpha-X B P 1-G R P 78$. Cancer Med 7:62346246. 10.1002/cam4.1862

Zhang Q, Itagaki K, and Hauser CJ. 2010a. Mitochondrial DNA is released by shock and activates neutrophils via p38 map kinase. Shock 34:55-59. 10.1097/SHK.0b013e3181cd8c08

Zhang Q, Raoof M, Chen Y, Sumi Y, Sursal T, Junger W, Brohi K, Itagaki K, and Hauser CJ. 2010b. Circulating mitochondrial DAMPs cause inflammatory responses to injury. Nature 464:104-107. 10.1038/nature08780

Zhang TH, Liang LZ, Liu XL, Wu JN, Su K, Chen JY, and Zheng QY. 2019b. LncRNA UCA1/miR-124 axis modulates TGF $\beta 1$-induced epithelial-mesenchymal transition and invasion of tongue cancer cells through JAG1/Notch signaling. J Cell Biochem 120:10495-10504. 10.1002/jcb.28334

Zhong W-Q, Ren J-G, Xiong X-P, Man Q-W, Zhang W, Gao L, Li C, Liu B, Sun Z-J, Jia J, Zhang W-F, Zhao Y-F, and Chen G. 2019. Increased salivary microvesicles are associated with the prognosis of patients with oral squamous cell carcinoma. Journal of cellular and molecular medicine 23:4054-4062. 10.1111/jcmm.14291

Zhou H, Pisitkun T, Aponte A, Yuen PS, Hoffert JD, Yasuda H, Hu X, Chawla L, Shen RF, Knepper MA, and Star RA. 2006. Exosomal Fetuin-A identified by proteomics: a novel

Peer) reviewing PDF | (2020:06:49854:1:1:NEW 26 Aug 2020) 
urinary biomarker for detecting acute kidney injury. Kidney Int 70:1847-1857. 10.1038/sj.ki.5001874

1261

1262

1263

1264

orski-Hurvitz A, Dayan D, Chaushu G, Salo T, and Vered M. 2016. Morphological and

1265 molecular features of oral fluid-derived exosomes: oral cancer patients versus healthy individuals. J Cancer Res Clin Oncol 142:101-110. 10.1007/s00432-015-2005-3 


\section{Table $\mathbf{1}$ (on next page)}

NCRNAs regulating the process of OSCC in exosomes 
1 Table 1. NcRNAs regulating the process of OSCC in exosomes

\begin{tabular}{|c|c|c|c|c|c|c|}
\hline NcRNAs & $\begin{array}{l}\text { Types of } \\
\text { ncRNAs }\end{array}$ & $\begin{array}{l}\text { Pro /Anti- } \\
\text { tumor }\end{array}$ & $\begin{array}{c}\text { Target/Signal } \\
\text { pathway }\end{array}$ & Functions & $\begin{array}{l}\text { Origin of } \\
\text { exosomes }\end{array}$ & Ref. \\
\hline $\operatorname{miR} 8485$ & miRNA & Pro-tumor & - & $\begin{array}{lr}\text { Promote } & \text { the } \\
\text { carcinogenesis } & \text { of } \\
\text { premalignant } & \text { lesions, } \\
\text { proliferation, migration } \\
\text { and invasion of tumor } \\
\text { cells }\end{array}$ & MSCs & [133] \\
\hline $\begin{array}{l}\text { miR-6887- } \\
\quad 5 \mathrm{p}\end{array}$ & miRNA & Anti-tumor & $\begin{array}{l}\text { HBp 17/FGFB } \\
\text { P-1 }\end{array}$ & $\begin{array}{l}\text { Inhibit tumor cell } \\
\text { proliferation, colony } \\
\text { formation, then tumor } \\
\text { growth }\end{array}$ & A431 cells & [139] \\
\hline $\begin{array}{l}\text { miR-142- } \\
\quad 3 p\end{array}$ & miRNA & Pro-tumor & TGFBR1 & $\begin{array}{l}\text { Cause tumor-promoting } \\
\text { changes }\end{array}$ & $\begin{array}{c}\text { Oral } \\
\text { dysplasia and } \\
\text { OSCC cell } \\
\text { lines }\end{array}$ & [138] \\
\hline miR-24-3p & miRNA & Pro-tumor & PER1 & $\begin{array}{l}\text { Maintain the proliferation } \\
\text { of OSCC cells }\end{array}$ & $\begin{array}{c}\text { Saliva in } \\
\text { OSCC } \\
\text { patients }\end{array}$ & [132] \\
\hline miR-3188 & miRNA & Anti-tumor & BCL2 & $\begin{array}{l}\text { The loss of miR-3188 in } \\
\text { exosomes contributes to } \\
\text { the malignant phenotypes } \\
\text { of HNC cells through the } \\
\text { depression of BCL2 }\end{array}$ & CAFs & [140] \\
\hline $\begin{array}{l}\operatorname{miR}-34 a- \\
5 p\end{array}$ & miRNA & Anti-tumor & $\begin{array}{l}\text { AXL } \\
\text { AKT/GSK- } \\
\text { 3beta/beta- } \\
\text { catenin } \\
\text { signaling } \\
\text { pathway }\end{array}$ & $\begin{array}{l}\text { MiR-34a-5p binds to } \\
\text { direct downstream target } \\
\text { AXL to suppress OSCC } \\
\text { cell proliferation and } \\
\text { metastasis }\end{array}$ & CAFs & [145] \\
\hline $\operatorname{miR} 3825 p$ & miRNA & Pro-tumor & - & $\begin{array}{l}\text { Responsible for } \mathrm{OSCC} \\
\text { cell migration and } \\
\text { invasion }\end{array}$ & CAFs & [141] \\
\hline miR-21-5p & miRNA & Pro-tumor & - & $\begin{array}{l}\text { Increase metastasis, } \\
\text { stemness, } \\
\text { chemoresistance and poor } \\
\text { survival in patients with } \\
\text { OSCC }\end{array}$ & $\begin{array}{l}\text { CAL27 and } \\
\text { SCC-15 } \\
\text { OSCC cells }\end{array}$ & [144] \\
\hline $\operatorname{miR}-1246$ & miRNA & Pro-tumor & $\begin{array}{l}\text { DENND2D } \\
\text { ERK/AKT }\end{array}$ & $\begin{array}{l}\text { Increase cell motility and } \\
\text { invasive ability }\end{array}$ & $\begin{array}{l}\text { HOC313-LM } \\
\text { OSCC cells }\end{array}$ & [134] \\
\hline
\end{tabular}




\begin{tabular}{|c|c|c|c|c|c|c|}
\hline \multirow[t]{2}{*}{ miR-21 } & miRNA & Pro-tumor & $\begin{array}{c}\text { pathway } \\
\text { miR-21/HIF- } \\
\text { 1alpha/HIF- } \\
\text { 2alpha- } \\
\text { dependent } \\
\text { pathway }\end{array}$ & $\begin{array}{l}\text { MiR-21 can be delivered } \\
\text { to normoxic cells to } \\
\text { promote prometastatic } \\
\text { behaviors }\end{array}$ & $\begin{array}{c}\text { Hypoxic } \\
\text { OSCC cells }\end{array}$ & [143] \\
\hline & & Pro-tumor & $\begin{array}{l}\text { PTEN, } \\
\text { PDCD4 }\end{array}$ & $\begin{array}{l}\text { Induce cisplatin } \\
\text { resistance of OSCC cells }\end{array}$ & $\begin{array}{l}\text { HSC-3-R and } \\
\text { SCC-9-R }\end{array}$ & [153] \\
\hline $\begin{array}{l}\operatorname{miR}-200 c- \\
\quad 3 p\end{array}$ & miRNA & Pro-tumor & CHD9, WRN & $\begin{array}{l}\text { Spread invasive capacity } \\
\text { by exosomes in tumor } \\
\text { microenvironment }\end{array}$ & $\begin{array}{l}\text { SQUU-B } \\
\text { tongue cancer } \\
\text { cell clones }\end{array}$ & [142] \\
\hline $\operatorname{miR}-155$ & miRNA & Pro-tumor & - & $\begin{array}{l}\text { Lead to mesenchymal } \\
\text { transition and increase } \\
\text { migratory potential and } \\
\text { acquire cells drug- } \\
\text { resistant phenotype }\end{array}$ & $\begin{array}{l}\text { Cisplatin } \\
\text { resistant } \\
\text { OSCC cells }\end{array}$ & [150] \\
\hline miR-200c & miRNA & Anti-tumor & $\begin{array}{l}\text { TUBB3, } \\
\text { PPP2R1B }\end{array}$ & $\begin{array}{l}\text { Increase the sensitivity of } \\
\text { Docetaxel } \\
\text { resistant HSC-3 cells to } \\
\text { DTX }\end{array}$ & $\begin{array}{c}\text { normal } \\
\text { tongue } \\
\text { epithelial } \\
\text { cells } \\
\text { (NTECs) }\end{array}$ & [151] \\
\hline $\begin{array}{l}\operatorname{miR}-101- \\
\quad 3 p\end{array}$ & miRNA & Anti-tumor & COL10A1 & $\begin{array}{l}\text { Overexpression of miR- } \\
101-3 p \text { inhibit oral cancer } \\
\text { progression and provide a } \\
\text { therapeutic target }\end{array}$ & $\begin{array}{l}\text { human bone } \\
\text { marrow } \\
\text { mesenchymal } \\
\text { stem cells } \\
\text { (hBMSCs) }\end{array}$ & {$[27]$} \\
\hline $\begin{array}{l}\operatorname{miR}-29 a- \\
3 p\end{array}$ & miRNA & Pro-tumor & SOCS1 & $\begin{array}{l}\text { Promote M2 subtype } \\
\text { macrophage polarization, } \\
\text { tumor cell proliferation } \\
\text { and invasion }\end{array}$ & $\begin{array}{l}\text { SCC-9 and } \\
\text { CAL-27 }\end{array}$ & [147] \\
\hline FLJ22447 & $\operatorname{lncRNA}$ & Pro-tumor & $\begin{array}{c}\text { Lnc-CAF/IL- } \\
33\end{array}$ & $\begin{array}{lr}\text { Reprogram } & \text { normal } \\
\text { fibroblast to } & \text { CAFs and } \\
\text { promote } & \text { OSCC } \\
\text { development } & \end{array}$ & CAFs & [164] \\
\hline
\end{tabular}

2 
Figure 1

Exosomes biogenesis and secretion within endosomal system

This figure is reprinted from the manuscript of Role of exosomal proteins in cancer diagnosis done by Li W et al. according to open access licence CC BY 4.0

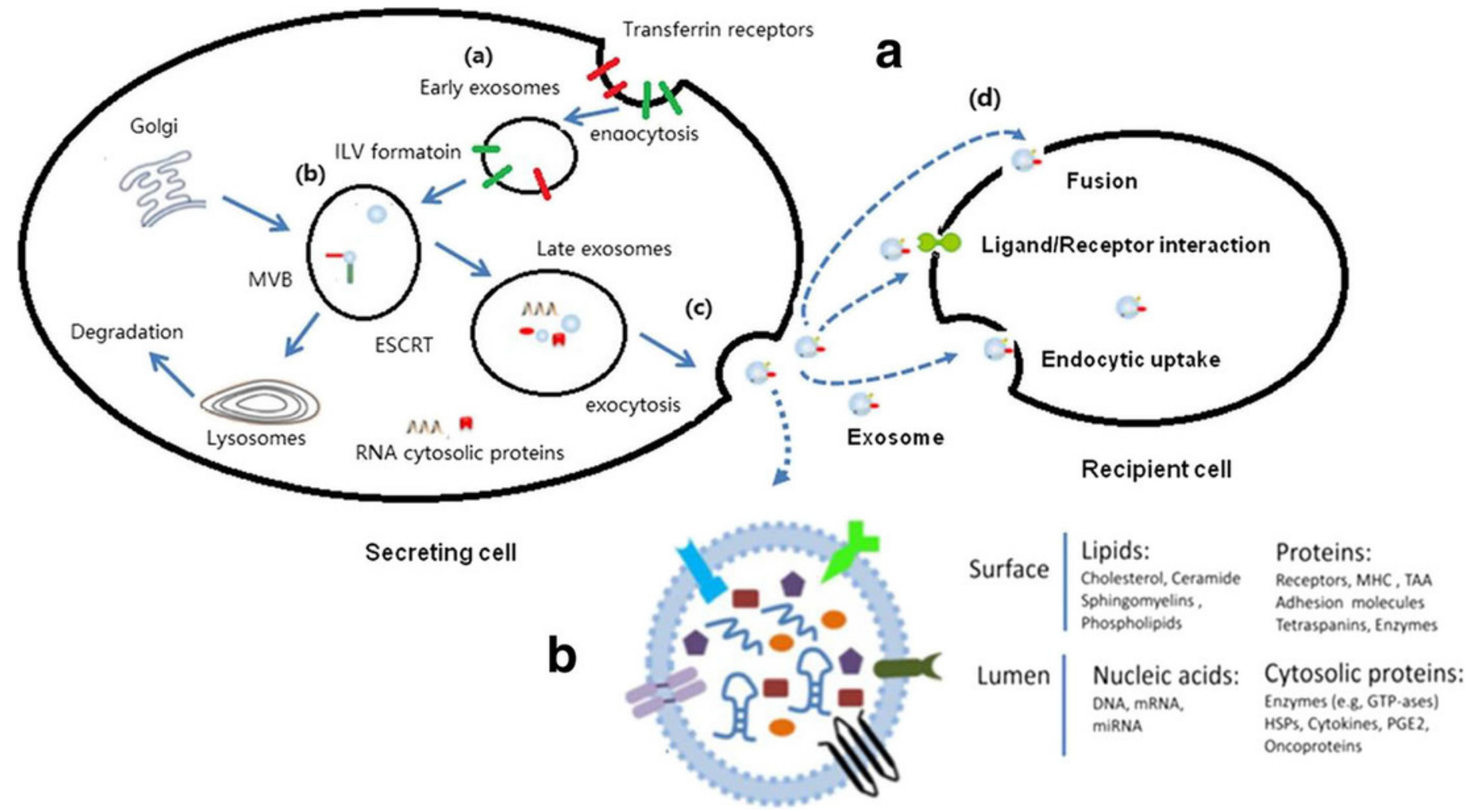


Figure 2

Exosomes' contents and potential functions in the developing process of OSCC

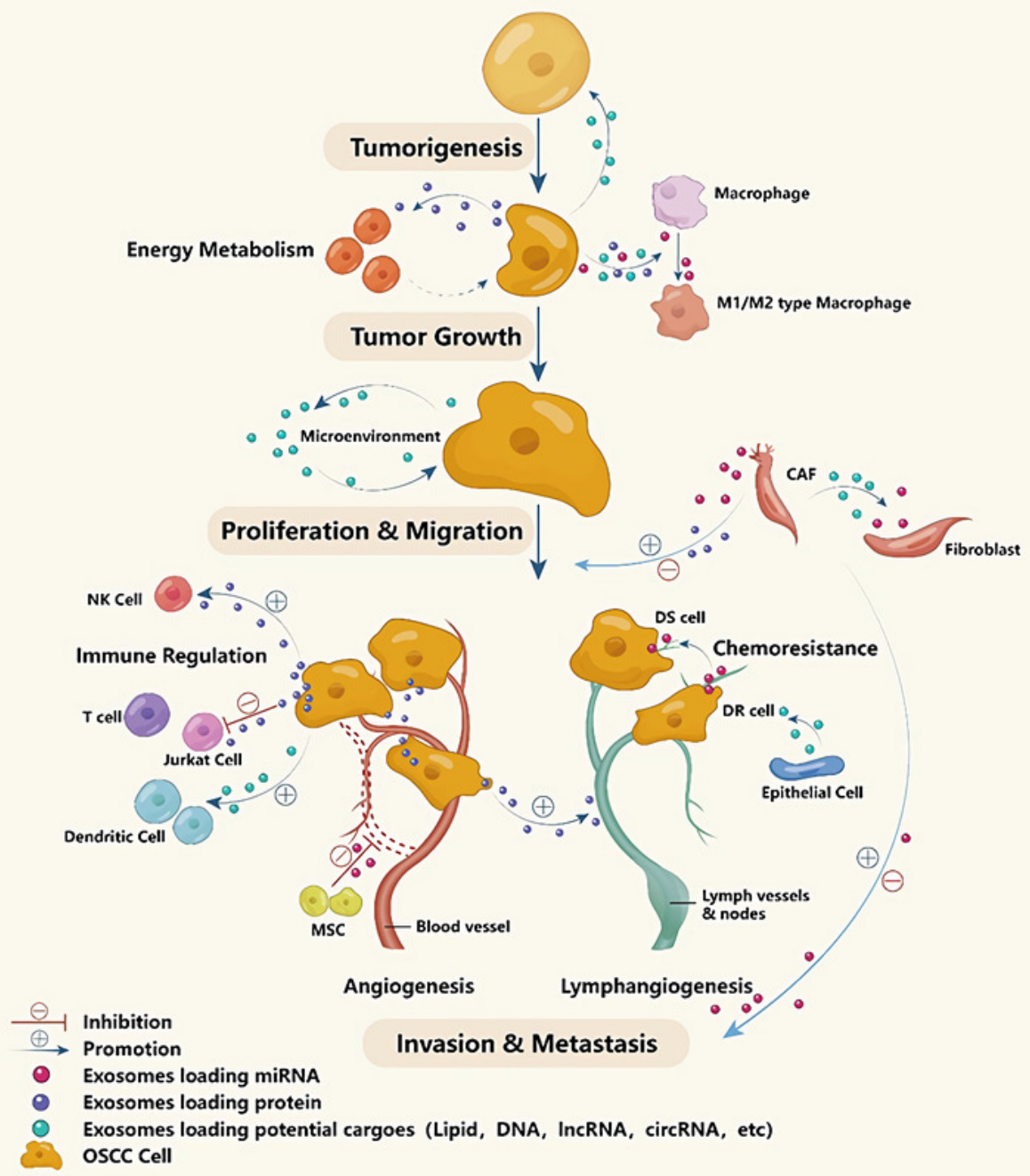


Figure 3

Functions of exosomes capsuled proteins in OSCC

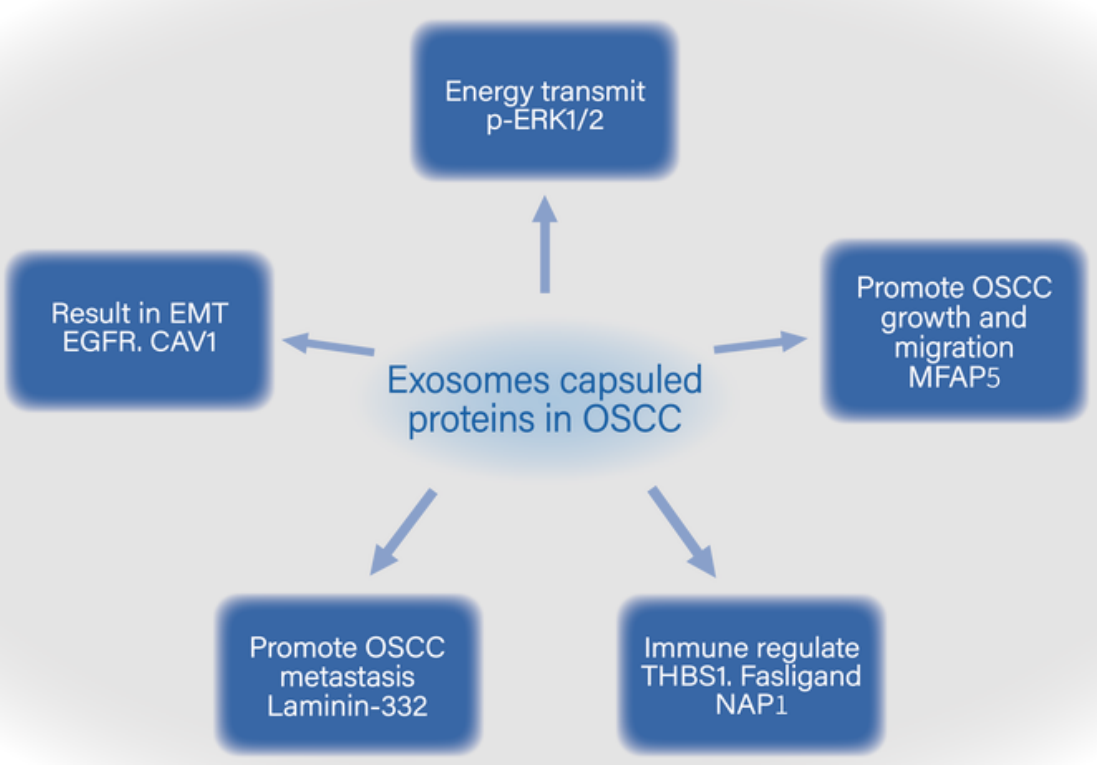

